\title{
Nutritional regulation of glucokinase: a cross-species story
}

\author{
Stéphane Panserat ${ }^{1 *}$, Nicole Rideau ${ }^{2}$ and Sergio Polakof ${ }^{3}$ \\ ${ }^{1}$ INRA, UR1067 Nutrition Metabolism Aquaculture (NUMEA), French National Institute for Agricultural Research (INRA), \\ Aquapôle, F-64310 Saint-Pée-sur-Nivelle, France \\ ${ }^{2}$ INRA, UR83 Recherches Avicoles, French National Institute for Agricultural Research (INRA), F-37380 Nouzilly, France \\ ${ }^{3}$ INRA, Human Nutrition Unit (UNH), French National Institute for Agricultural Research (INRA), Clermont-Ferrand/Theix \\ Research Centre, F-63122 Saint-Genès-Champanelle, France
}

\section{Abstract}

The glucokinase (GK) enzyme (EC 2.7.1.1.) is essential for the use of dietary glucose because it is the first enzyme to phosphorylate glucose in excess in different key tissues such as the pancreas and liver. The objective of the present review is not to fully describe the biochemical characteristics and the genetics of this enzyme but to detail its nutritional regulation in different vertebrates from fish to human. Indeed, the present review will describe the existence of the GK enzyme in different animal species that have naturally different levels of carbohydrate in their diets. Thus, some studies have been performed to analyse the nutritional regulation of the GK enzyme in humans and rodents (having high levels of dietary carbohydrates in their diets), in the chicken (moderate level of carbohydrates in its diet) and rainbow trout (no carbohydrate intake in its diet). All these data illustrate the nutritional importance of the GK enzyme irrespective of feeding habits, even in animals known to poorly use dietary carbohydrates (carnivorous species).

\section{Key words: Glucokinase: Humans: Fish: Birds: Carbohydrates}

\section{Introduction}

The glucokinase (GK) enzyme, also known as hexokinase (HK) IV (or D), is one of the four glucose-phosphorylating isoenzymes described initially in the vertebrate liver, characterised by a low affinity for glucose, sigmoidal kinetics and lack of inhibition by glucose-6-phosphate. The others, being called HK I (or A), II (or B) and III (or C), are more widely distributed and do not meet the characteristics cited above ${ }^{(1,2)}$. This enzyme has been the object of numerous studies mainly because of its role in hepatic metabolism, but also in glucose homeostasis, given its involvement in metabolism-dependent insulin secretion. In the latter case, research has been focused on the role of GK in type 2 diabetes mellitus. Very good reviews about the biochemical and molecular regulation of GK can be found in the literature and the reader is encouraged to consult those of Printz et al. ${ }^{(3)}$, Iynedjian ${ }^{(4)}$, Cárdenas ${ }^{(5)}$ and Matschinsky ${ }^{(6,7)}$.

Most of the reviews published so far have dealt with the role and regulation of GK in the rodent model applied to human pathophysiological issues ${ }^{(7)}$. In the present review we will not concentrate on the pharmacological or molecular regulation of the mammalian GK, as this topic has been approached on numerous occasions (see above). Rather, we will focus our attention on the nutritional regulation of the enzyme. In this sense, comparative studies of glucose-phosphorylating activity in the liver have shown that in regular conditions (standard diet) the number of isoenzymes may vary as a function of the species and that GK appears to be absent in several of them $^{(8)}$ (see Fig. 1). Moreover, other questions remain unresolved, including a different nutritional regulation of hepatic and pancreatic GK (due to different promoters) and the possibility that in some animal species GK has not been detected due to the lack of nutritional induction or evolutionary reasons (such as loss of the gene or conversion to a pseudogene). Beyond the well-known rodent model for the study of GK, in the present review we explore the knowledge accumulated concerning the nutritional regulation of GK in other animal species with different nutritional habits and then alternative mechanisms of glucose regulation.

Thus, our objective is twofold: on one hand, to offer a glance over the knowledge about GK in other vertebrate groups, such as fish and birds, but also in rarely explored

Abbreviations: GK, glucokinase; GKA, GK activator; GKR, glucokinase regulator; GKRP, glucokinase regulatory protein; HC, high carbohydrate; HF, high fat; HK, hexokinase; $K_{\mathrm{m}}$, Michaelis constant; mRNA, messenger RNA.

*Corresponding author: Dr Stephane Panserat, fax +33 5595451 52, email panserat@st-pee.inra.fr 
mammalian species, such as cats and dogs. On the other hand, we aim to make a comparative analysis of the nutritional regulation of GK between the classical mammalian models and the other groups in which GK is differentially

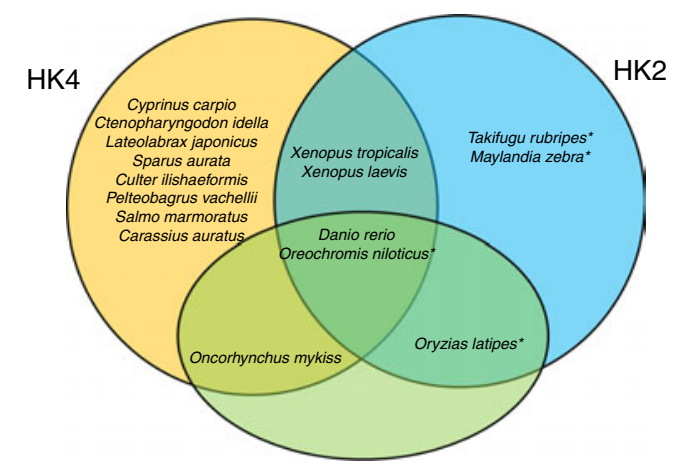

Fish and amphibians

HK1

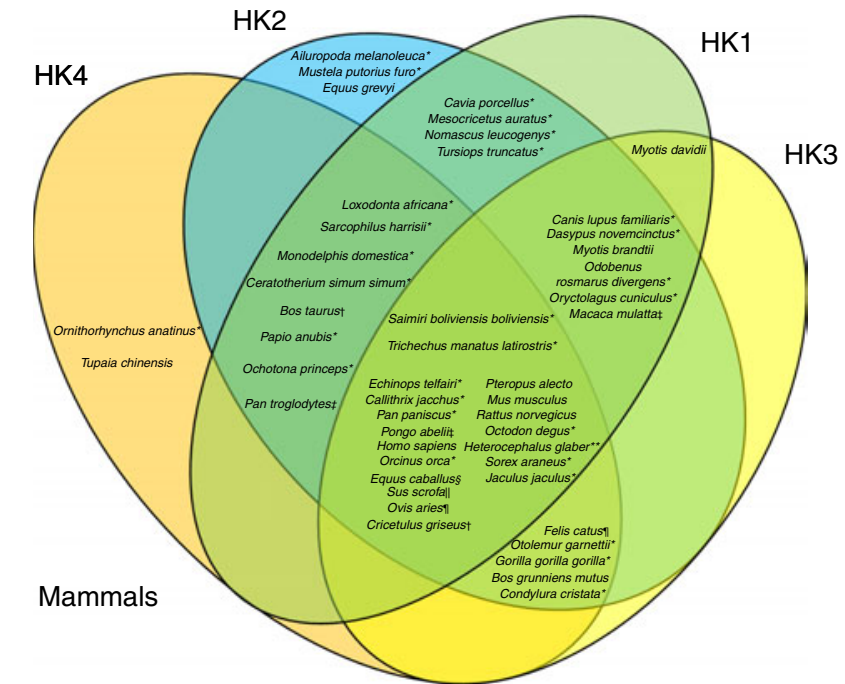

Fig. 1. Venn diagrams representing the putative presence of the four hexokinase $(H K)$ isoforms (HK1, HK2, HK3, HK4) in fish and amphibians, reptiles and birds, and mammals. The represented data were obtained from the National Center for Biotechnology Information (NCBI) protein database. * Predicted sequences. † Predicted HK2. ‡ Predicted sequences except HK1. $\S$ Predicted sequences except HK2. [capsverbar] Predicted sequences except HK1 and HK2. ๆ Predicted sequences except HK4. ${ }^{* *}$ Predicted sequence HK1. (A colour version of this figure can be found online at http://www. journals.cambridge.org/nrr). regulated based on different evolutionary pressures and nutritional habits. Finally, several outputs will be discussed from a perspective point of view, including: (i) other nutritional roles for GK (other than those related to hepatic glucose metabolism and insulin secretion); (ii) implications in human nutrition from data obtained in genome-wide association studies; and (iii) impact on the context of deleterious diets (rich in fat or carbohydrates) for some species and not for others.

\section{Glucokinase in mammals}

Among vertebrates, the mammals are without discussion the best-represented group concerning the study of GK. Actually, the enzyme was discovered in rats, which became very quickly the best model for studying human GK: $37 \%$ of the papers published on GK are focused on the rat GK, while $42 \%$ are studies in human subjects, a number importantly boosted by pharmacological and mutation studies. After mice (16\%), the rest of mammalian species (all of them below $2 \%$ ) seem not to have attracted the attention of scientists (see Fig. 2). This may be due to the fact that GK activity has been found in twenty-two mammalian species, twelve of them rodents (see Table 1). In contrast, at the protein level a similar number of species express GK, but most of them are primates (Fig. 3). In this sense, the biggest cluster includes the primates and rodents, while the rest of the species are classified in more or less diverse groups. It is worth mentioning that nutritional habits do not seem to have an impact on this classification.

GK in mammals has been mainly studied in rodent species, such as the rat (Rattus norvegicus) and the mouse (Mus musculus), and, when possible, in human biopsy samples. More recently, some research teams have been also put some attention to the regulation of GK in other species of interest, such as domestic cats and dogs, although the level of knowledge remains quite limited.

\section{Glucokinase function and regulation in mammals}

The GK enzyme is a glucose-phosphorylating enzyme initially discovered in rat liver in the early 1960s. The rapid characterisation of its biochemical properties led to the idea that GK was actually the key regulator enzyme of hepatic glucose metabolism. As a matter of fact, GK does not work as any other HK found in eukaryotic cells, given that it is not inhibited by the product of the reaction that it catalyses (glucose-6-phosphate), has a low affinity for glucose $\left(\mathrm{S}_{0.5}\right.$ about $\left.7.5 \mathrm{~mm}\right)$ and a characteristic sigmoidal kinetics (Hill coefficient about 1.6). Thanks to these characteristics, GK is able to cope and handle the postprandial glucose increase observed after a meal. Given its importance in the postprandial regulation of glucose metabolism, it is not surprising that GK is tightly regulated by insulin. 

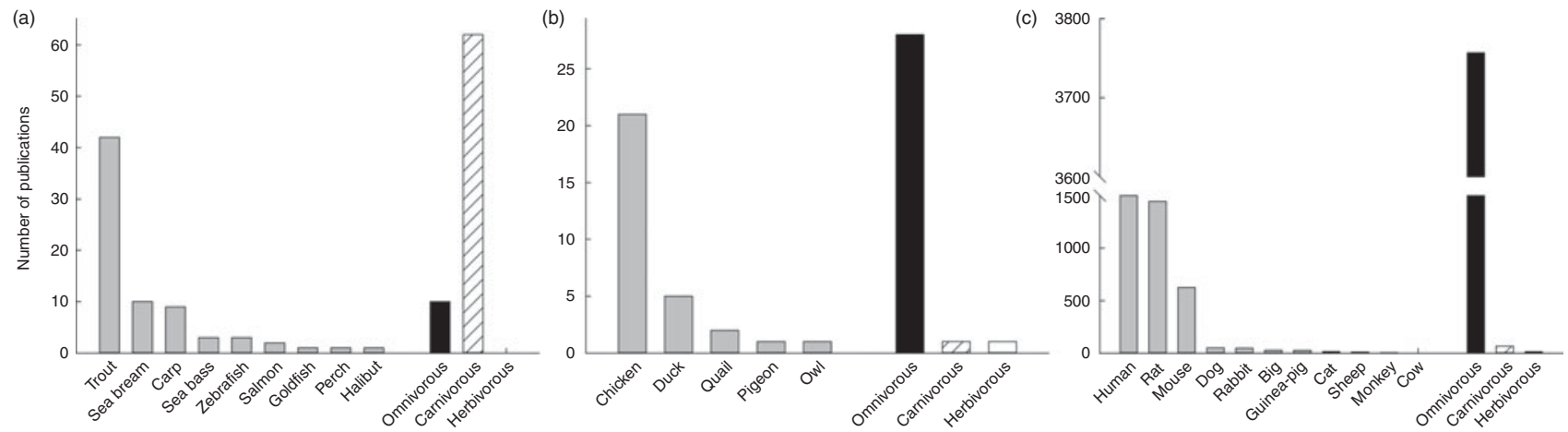

Fig. 2. Representation of the number of publications concerning the enzyme glucokinase in three groups of vertebrates: fish (a), birds (b) and mammals (c). Amphibians and reptiles were omitted given the low number of publications $(<5)$. For each group, the number of publications $(>1)$ per species was included, as well as the total number of publication depending on nutritional and feeding habits. Data were obtained from Scopus (Copyright ${ }^{\mathcal{C}} 2013$ Elsevier B.V.) using the key words 'glucokinase' and the searched species (i.e. 'rat' or 'chicken').

Very soon GK was also reported to be present in laboratory animals ${ }^{(9)}$ and human pancreatic tissue ${ }^{(10)}$, and then its role in glucose homeostasis as a glucosensor was proposed $^{(11)}$. This was further supported by the fact that GK is encoded by a single gene, but controlled by two specific promoters: one hepatic and one pancreatic ${ }^{(12,13)}$. More recently, the GK network has been largely enriched as GK has been found in several other cellular types, including neurons (glucose excited and glucose inhibited), enteroendocrine cells ( $\mathrm{K}$ and $\mathrm{L})^{(14)}, \alpha$-cells $^{(15)}$ and pituitary gonadotropes $^{(16)}$.

The presence of GK in rodent pancreatic tissue was discovered more than 20 years ago ${ }^{(17)}$, and given that the activity of pancreatic GK is glucose dependent, this enzyme is today inseparable from the glucose sensor concept $^{(18,19)}$. The GK glucose sensor paradigm is integrated with the threshold concept for glucose-stimulated insulin release, given that GK constitutes the rate-limiting step in the generation of a trigger metabolite of a constellation of metabolic signals initiating the secretory process. Since its discovery, pancreatic GK has been extensively studied, given that more than 150 mutations have been discovered in the pancreatic GK gene that alters this glucosensing capacity. However, while most of the energy of the scientists has been directed to this aspect, very little has been done in the nutritional field, and the behaviour of GK in pancreatic tissue under different real nutritional conditions is still only partially known.

GK is known to be tightly regulated at numerous levels, including modifications of conformational status, physical interaction with other proteins, hormonal control and a tissue-dependent molecular expression.

The most rapid regulation of GK takes place at the conformational level given the cooperativity of its kinetics with regard to D-glucose. GK has two conformations, an active and an inactive form with high and low glucose affinity, respectively, which allow optimal substrate sensitivity at the fasting level of blood glucose in humans and many laboratory animals ${ }^{(20)}$. The second level of regulation in terms of rapidity would be its interaction with the bifunctional enzyme 6-phosphofructo-2-kinase/fructose-2,6-biphosphatase $(6 \mathrm{PF} 2 \mathrm{~K} / \mathrm{F} 26 \mathrm{P} 2 \mathrm{ase})^{(21)}$ and the $\mathrm{GK}$ regulatory protein (GKRP). While in the first case very little is known, more information is available concerning the GKRP regulation of GK. The actual ligands for this protein are fructose-1phosphate and fructose-6-phosphate, which have antagonist effects on the GK-GKRP binding tandem: while GKRP binds to GK and inhibits the enzyme activity competitively with respect to glucose, fructose-6-phosphate reinforces the inhibitory effect of GKRP and fructose-1-phosphate abolishes binding and subsequent inhibition ${ }^{(22,23)}$. Later, other authors showed that this was only a partial description of the regulation mechanism and that the main feature of GKRP was that this protein sequesters GK in the nucleus in the absence of a high concentration of glucose or fructose ${ }^{(24,25)}$. In the opposite conditions (i.e. high glucose or fructose concentration), GK is released by GKRP and translocates into the cytoplasm where it exerts its action. Long-term GK control is mainly exerted by hormones and GK expression control. Hormonal stimulation is able to induce (insulin) or repress (glucagon) GK expression, protein and activity. Maybe the major feature of the regulation of GK expression is the dual control of this enzyme by insulin in the liver and by glucose in the pancreatic $\beta$-cells, which is based on the existence of a downstream and an upstream promoter within the GK gene - the 'one gene, two promoters' concept for control of GK expression ${ }^{(4)}$. Finally, other levels of regulation include the epigenetic hypermethylation of the GK gene (age-related, in a way that increased methylation is negatively associated with hepatic GK expression ${ }^{(26)}$ ), and GK nitration, that leads to pancreatic ${ }^{(27)}$ and hepatic inactivation of the enzyme ${ }^{(28)}$.

\section{Nutritional regulation of glucokinase in mammals}

Very few studies have focused on the macro- and micronutrient interactions and regulation of this enzyme. Given that the micronutrient effects are only known in some mammalians species ${ }^{(29-31)}$, in the present review we will focus on 
Table 1. Glucokinase activity in the liver of forty-two vertebrate species, including twenty-two mammals, seven birds, three reptiles, two amphibians and eight fish*

\begin{tabular}{lccc}
\hline Species & $\begin{array}{c}\text { Activity } \\
\text { (U/g liver) }\end{array}$ & $\begin{array}{c}\text { Activity } \\
\text { (mU/mg protein) }\end{array}$ & $\begin{array}{c}\text { Tissue preparations } \\
\text { and assay conditions }\end{array}$ \\
\hline
\end{tabular}

Mammals

Degu (Octodondegus)

Field mouse (Akodonolivaceus)

Long-haired mouse (Akodon longipilis)

Leaf-eared mouse (Phyllotis darwini)

Hamster (Mesocricetus auratus)

Guinea-pig (Carla porcellus)

Coipo (Myocastor coypu)

Cururo (Spalacopus cyanus)

Squirrel monkey (Saimiri scuirea)

Marsupial yaca (Marmosa elegans)

Sheep (Ovis aries)

Camel (Camelus dromedaries)

Possum (Trichosurus vulpecula)

Rabbit (Oryctolagus cuniculus)

Dog (Canis familiaris)

Pig (Sus scrofa)

Man (Homo sapiens)

Mouse (Mus musculus)

Rat (Rattus norvergicus)

Sand rat (Merianes hurrianae)

Gerbil (Cricetidae gerbillus)

Cat (Felis domesticus)

Birds

Finch (Serinus canaries)

Chicken (Gallus gallus)

Pigeon (Columba livia)

Mallard (Pekin) (Ana splatyrhynchos)

Mule duck (male Cairina moschata $\times$ female Anas plathyrhynchos)

Muscovy (Cairina moschata)

Hinny (male Anas plathyrhynchos $\times$ female Cairina moschata)

Reptiles

Spotted turtle (Cleramys guttala)

Argentine tortoise (Geochelone chilensis)

Argentine snake-necked turtle (Hydromedusa tectifera)

Amphibians

American bullfrog tadpole (Rana catesbeiana) $\dagger$

Salamander (Ambystom amacu)

Fish

Goldfish (Carassius auratus)

Trout (Oncorhynchus mykiss)

Gilthead sea bream (Sparus auratus)

Common carp (Cyprinus carpio)

Atlantic salmon (Salmo salar)

Atlantic halibut (Hippoglossu shipoglossus)

European sea bass (Dicentrarchus labrax)

Blackspot sea bream (Pagellus bogaraveo)

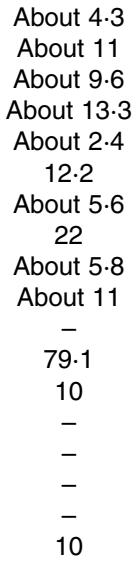

$1 \cdot 8$

$3 \cdot 2$

$\overline{1 \cdot 01}$

$3 \cdot 8$

$3 \cdot 2-5 \cdot 7$

$-$

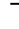

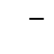

$0-0 \cdot 1$

$0.1-0.3$

0.40

0.60

0.45

$-$

$-$

$0 \cdot 2-1 \cdot 8$

$-$

$-$

$-$

$0 \cdot 15$

0.13

$-$

- $\quad 1.6$

$2 \cdot 1$

- $\quad 3.3-55.2$

- $\quad 1.0-29.9$

- $\quad 1.1-9.7$

- $\quad 6.0-9.4$

$5.2-13.5$
$-\quad 27.1-98.4$

- $\quad 0.6-9.6$

$0.1 \quad 0.7-0.9$
- 251

- 251

$-\quad 251$

- 251

$105000 \mathrm{~g}$

252

251

252

251

251

251

252

251

253

253

254

254

251

41

254

254

252

63

41

41,255

Fasted and fed activities

12 000-100 $000 \mathrm{~g}$

Fed and fasted

$27000-100000 \mathrm{~g} \quad 41,44$

$105000 \mathrm{~g} 252$

$105000 \mathrm{~g}$

$105000 \mathrm{~g} 252$

$105000 \mathrm{~g}$

$600-900 \mathrm{~g}$

$27000 \mathrm{~g}$

$100000 \mathrm{~g}$

$100000 \mathrm{~g}$

$100000 \mathrm{~g}$

$900 \mathrm{~g}$

$900 \mathrm{~g}$

$27000 \mathrm{~g}$

$900 \mathrm{~g}$

$900 \mathrm{~g}$

$105000 \mathrm{~g}$

$40000 \mathrm{rpm}$

$40000 \mathrm{rpm}$

$160,164,200,256$

158

41

41

41

183

183

151

183

183

252

257

257

$105000 \mathrm{~g}$

252

$105000 \mathrm{~g}$

252

$900 \mathrm{~g}$

$105000 \mathrm{~g}$

$900 \mathrm{~g}$

$900 \mathrm{~g}$

$900 \mathrm{~g}$

$900-100000 \mathrm{~g}$

0-30\% starch

900-100 $000 \mathrm{~g}$

Brockmann bodies

$900 \mathrm{~g}$

$900 \mathrm{~g}$

47

252

165

165

165

154, 198

242

224

258

* When possible, activities were expressed in both $\mathrm{U} / \mathrm{g}$ liver and $\mathrm{mU} / \mathrm{mg}$ protein. When available, different extraction procedures were included.

† Renamed Lithobates catesbeianus. 


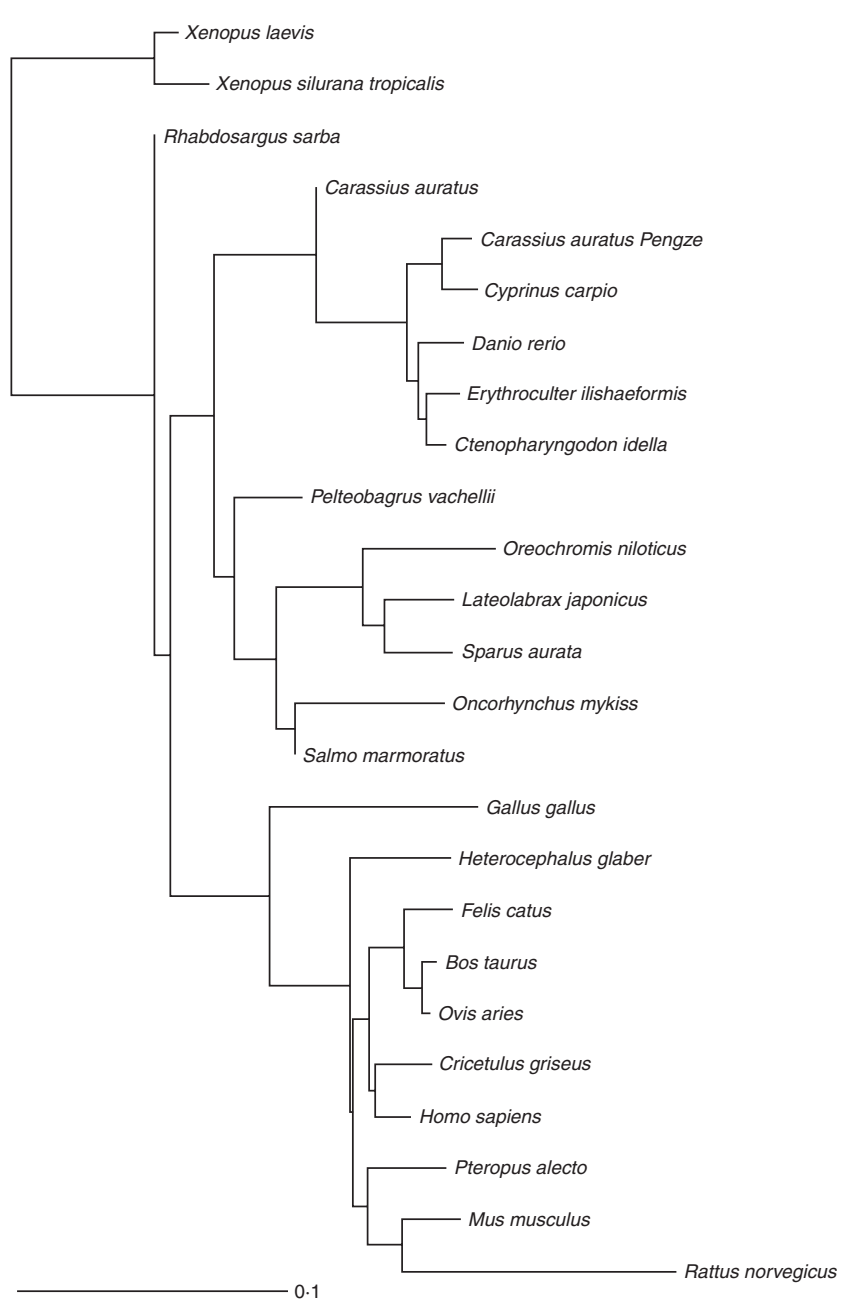

Fig. 3. Glucokinase protein multiple alignment between sequences of forty vertebrate species, including thirteen fish, two amphibians, one bird and nine mammals available at the National Center for Biotechnology Information (NCBI) protein database. Multiple progressive alignment was done using COBALT (Constraint-based Multiple Protein Alignment Tool) ${ }^{(249)}$. The picture was created using TreeViewX from the Nexus file obtained after COBALT analysis. Protein accession numbers are available upon request.

the nutritional impact of macronutrients and more in general the nutritional status of the animals on GK regulation.

Despite the lack of human data on GK we do know, thanks to studies developed in rodents, that nutrition plays a key role in GK regulation and that all the macronutrients seem to have an important impact on this enzyme. In rodents, high fat (HF) feeding results in reduced hepatic and pancreatic GK activity and impaired glucose tolerance. In contrast, short-term fructose feeding in human subjects seems to have a beneficial effect on glycaemia control, given that it would be able to release GK from the GKRP binding, allowing increased hepatic glucose uptake ${ }^{(32,33)}$. However, longer studies in human subjects do not confirm these results and chronic fructose feeding in animals clearly leads to hepatic steatosis and insulin resistance ${ }^{(34)}$. In this sense, it is worth mentioning that the hepatic metabolism of fructose is not completely equivalent to that of glucose. While glucose metabolism is regulated by insulin and controlled by GK and phosphofructokinase (regulated by the level of ATP), fructose conversion to triose phosphate is an insulin-independent process and very fast (given the low Michaelis constant $\left(K_{\mathrm{m}}\right)$ of the fructokinase enzyme $)^{(35)}$. Moreover, this fructose metabolism is not regulated by ATP or citrate levels, leading to a transient depletion of free phosphate and a decrease in ATP in liver cells in response to fructose.

Given the increasing consumption of cafeteria-like diets (very rich in fat) and fructose syrup-based soft drinks in Western countries, the potential impact of fats and fructose feeding on human GK should not be ignored.

Studies on the nutritional regulation of GK in non-rodent animals are much less abundant. The interest in GK could be divided into two groups: on the one hand GK could be important to species of commercial interest such as livestock. However, most of them (ruminants) do not rely of glucose as primary fuel and then the role of GK remains to be elucidated. In single-stomached species (such as pigs, horse, rabbits) GK has been barely approached and then its importance is still unknown. On the other hand, in recent years the presence of GK in domestic species such as cats and dogs has been extensively studied, given that these species (with important protein requirements) are currently fed high-carbohydrate (HC)/HF diets with a low cost when comparing with protein. As a result, an important part of the canine and feline population is obese and diabetic and a possible role of GK in this new animal epidemic has been suggested.

Given the key role of GK on glucose metabolism and homeostasis, we will focus the present review on two groups of mammals depending on their metabolic and nutritional orientation: species relying mainly on glucose as a primary energy fuel (omnivorous and some herbivorous) and those that utilise other sources of nutrients, such as protein or fat (mainly carnivorous).

\section{Carbohydrate-dependent mammalian species}

Most of the available information on GK nutritional regulation came from fasting-refeeding cycle experiments, and the role of GK under different feeding regimens and diets is almost unknown. In the next sections of the review we will use as reference the data published on rodent species, stressing the data coming from other species when they do exist.

Glucokinase regulation by nutritional status: focus on fed-fasted-refeeding cycles and postprandial changes liver. The early studies that focused on GK showed that, in the liver, GK activity is highly affected by nutritional status, being inhibited by a classical $48 \mathrm{~h}$ food-deprivation protocol ${ }^{(36-38)}$, and practically undetectable after $72 \mathrm{~h}$ of fasting $^{(39,40)}$ (Table 2 and Fig. 4). Given the key role of insulin in controlling GK activity, the reduction in GK activity during fasting has been traditionally related to the 


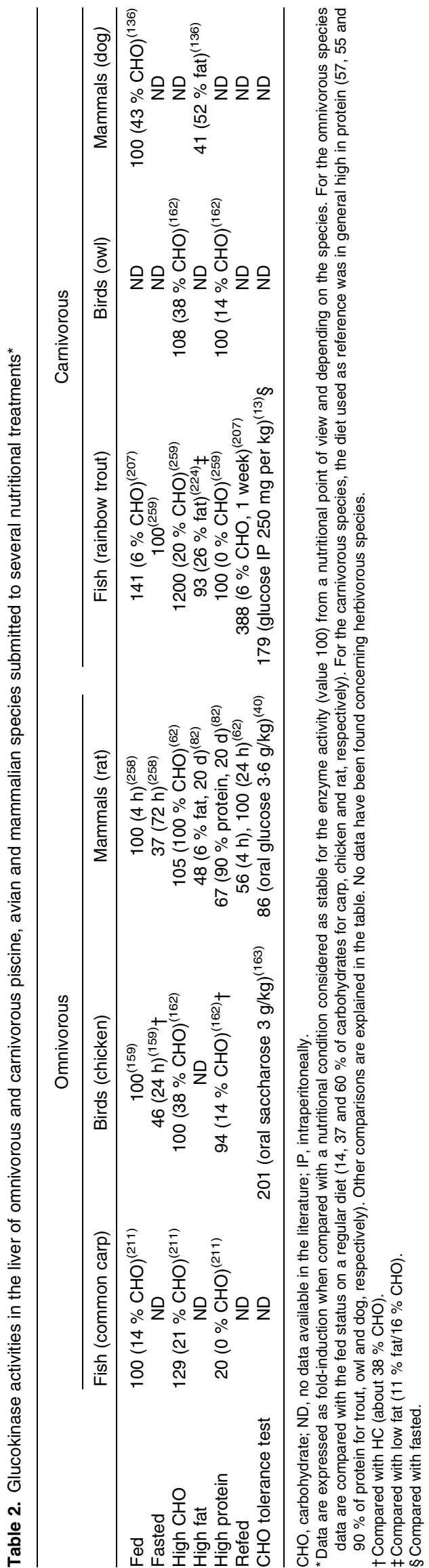

very low insulin levels during the food deprivation periods. Interestingly, GK activity in the liver of fasted human subjects (overnight) is quite low $(1-3.5 \mathrm{mU} / \mathrm{mg})^{(41)}$ when compared with 3-d fasted rodents (10 mU/mg), suggesting that the capacity of the human liver to handle dietary glucose is not as high as in rodents. This is in line with the fact that GK is detected in human liver biopsies but only when patients are well nourished, while in poorly nourished individuals the activity is undetectable ${ }^{(42)}$.

The molecular studies on GK showed that messenger RNA (mRNA) levels are strongly reduced in the fasted liver, while GK expression increases quickly when glucose is administrated ${ }^{(43)}$ (Table 2 and Fig. 4). The concentration of the GK protein in liver increases during the transition from the fasted to the refed state, similarly to the mRNA levels, which are undetectable in the liver of fasted rats, but which are strongly induced by a glucose load ${ }^{(17)}$. A very complete study by Iritani et al. ${ }^{(44)}$ showed in detail how GK activity and expression are regulated by feeding in the rat liver. Only $2 \mathrm{~h}$ after feeding a control diet $(67 \%$ carbohydrate) the mRNA levels of GK increased dramatically up to 20-fold when compared with the fasted state. At $8 \mathrm{~h}$ after feeding, this level of expression was already reduced $50 \%$, and $16 \mathrm{~h}$ after the meal the fasting level was achieved. In contrast, activity levels increased differentially, given that the first significant changes are observed $8 \mathrm{~h}$ after the meal, increasing the levels even $24 \mathrm{~h}$ after feeding.

The information available concerning the nutritional regulation of the GK-GKRP tandem is very scarce. GKRP quantity decreases with fasting and increases with refeeding ${ }^{(45)}$. Thus, disruption of the GK-GKRP complex and translocation of active GK to the cytosol has been reported during transition from the fasting $(24 \mathrm{~h})$ to refed ( 1 and $2 \mathrm{~h}$ refeeding) conditions in rats ${ }^{(46,47)}$.

Glucokinase regulation by nutritional status: focus on fed-fasted-refeeding cycles and postprandial changes pancreas. The earliest studies reported that the mRNA levels of pancreatic GK remained unaltered during the fed-fasting-refeeding cycle ${ }^{(17)}$. However, more recent papers showed that there exists a dependence on the nutritional state given that after $2 \mathrm{~d}$ of fasting the mRNA levels of GK were reduced by $50 \%$ when comparing with the fed control, while after $4 \mathrm{~h}$ of refeeding the expression was normalised ${ }^{(48)}$. Results obtained at the protein level are contradictory, given that in vivo studies did not detect any nutrient-dependent increase in freshly isolated islets from starved and refed rats ${ }^{(17)}$ or after infusion of glu$\operatorname{cose}^{(49)}$. However, GK protein did increase in vitro when pancreatic islets were incubated in the presence of high glucose concentrations, but for a long period $(3-7 \mathrm{~d})^{(50)}$. Contrary to the data obtained at the mRNA and protein levels, but consistent with the induction of pancreatic GK by insulin, GK activity in cytoplasmic fractions of pancreatic islets decreases with the duration of fasting and is increased by refeeding ${ }^{(51-53)}$. GK activity contributed 


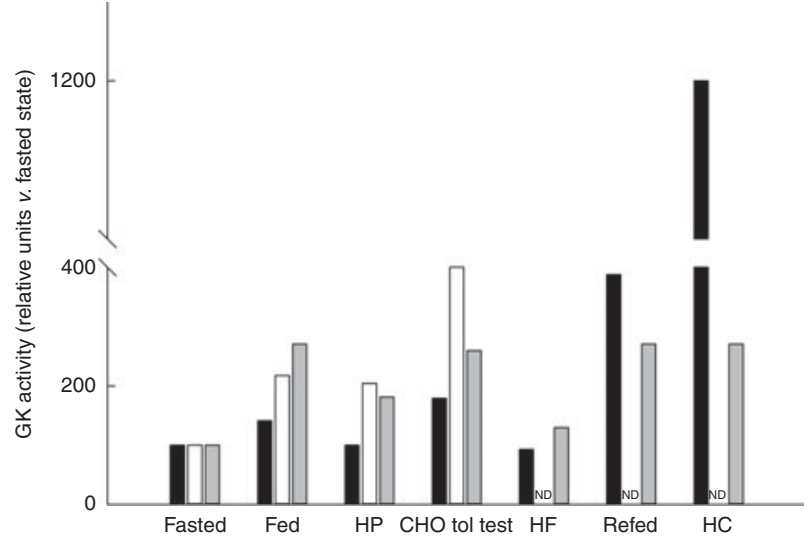

Fig. 4. Glucokinase (GK) activity in the liver of rainbow trout $(\square)$, chicken ( $\square$ ) and rat $(\square)$ submitted to different nutritional conditions, including fasting (24-72 h), regularly feeding, refeeding after fasting, response to a carbohydrate tolerance test ( $\mathrm{CHO}$ tol test) and to diets rich in carbohydrates (high carbohydrate; HC), protein (high protein; HP) and fat (high fat; HF). The fed status was based on the regularly used diet for each species, with a proportion of carbohydrates of 6,37 and $65 \%$ for trout, chicken and rat, respectively. The HF diet contained 15 and $65 \%$ of fat for trout and rat, and the HP diet contained 57,55 and $90 \%$ of protein for trout, chicken and rat. The tolerance test was made orally for chicken (saccharose $3 \mathrm{~g} / \mathrm{kg}$ ) and rat (glucose $3.6 \mathrm{~g} / \mathrm{kg}$ ), and intraperitoneally for trout (250 mg glucose $/ \mathrm{kg}$ ). The refeeding period was also dependent on the species: 1 week for trout and $24 \mathrm{~h}$ for rats. Data are presented as fold-induction when compared with the fasted group (value $=100$ ). ND, no data found in the literature. For more details and references, see Table 2.

about $75 \%$ to the total glucose phosphorylation capacity in cytoplasmic fractions of normal pancreatic islets. This has been later confirmed at the histological level, showing that the spatial pattern of intracellular GK distribution, rather than major changes in the absolute amounts of the enzyme protein ${ }^{(54)}$, parallels changes in the nutrient status of the animals ${ }^{(55)}$. The importance of pancreatic GK in human glucose homeostasis came from evidence obtained in GK mutants ${ }^{(56-58)}$. Here again, very little is known about how these mutants handle glucose homeostasis under a nutritional challenge. A very interesting study has been carried out by Klupa et $a l .{ }^{(59)}$ in which patients having ten different GK-inactivating mutations were fed either a low-carbohydrate diet (25\% of daily energy intake as carbohydrates) or a HC diet (60\% of daily energy intake as carbohydrates) for $2 \mathrm{~d}$. In all the cases, glycaemia was lower when feeding the low-carbohydrate diet, which seems to compensate for the non-functional GK and then promises a potential clinical impact when handling glucose homeostasis in these patients.

Regulation of glucokinase by dietary carbohydrates: liver. Data concerning the regulation of GK activity under different diets are essential in order to understand the nutritional role of this key enzyme. Unfortunately, studies focused in this topic are not abundant and only a few reports explored the combination of macronutrients as GK regulators. The early studies combining diets showed that GK worked properly only when rats were fed with a diet containing enough carbohydrates (Table 2). GK activity increased rapidly in rats in response to the feeding of both the high-glucose and high-fructose diets $^{(60)}$. The response to glucose is consistently greater than that to fructose. No change from fasting levels was observed in the groups fed diets containing no utilisable carbohydrate. In rats fed the high-glucose diet (60\% glucose), GK activity increased only $4 \mathrm{~h}$ after the start of feeding, while in the fructose-fed rats, the first change was noted at $12 \mathrm{~h}$. GK levels continued to increase over a $24 \mathrm{~h}$ period in the glucose-fed rats but not in the fructose-fed rats. Similarly, the expression of GK increased up to $6 \mathrm{~h}$ after feeding a HC diet $(57 \%$ of energy supplied by carbohydrates), with basal levels $18 \mathrm{~h}$ after the intake $^{(61)}$. In another similar approach, Perez et al. ${ }^{(62)}$ fasted rats for $48 \mathrm{~h}$, obtaining a $50 \%$ reduction in GK activity. At $6 \mathrm{~h}$ after being refed with a $100 \%$-carbohydrate diet, rats recovered their normal GK levels. Activity remained stable up to $72 \mathrm{~h}$ after the last meal. After $2 \mathrm{~d}$ on a HF diet ( $80 \%)$, activity was reduced by more than $50 \%$. In human subjects hepatic GK has been shown to be inducible by dietary carbohydrates $(400 \mathrm{~g} / \mathrm{d})^{(63)}$. Thus, the feeding of normal voluntary subjects with a carbohydrate-poor diet $(5 \mathrm{~g} / \mathrm{d})$ for $8 \mathrm{~d}$ caused a considerable decrease in GK activity measured in hepatic biopsy samples, while a $2 \mathrm{~d}$ feeding with a HC diet was enough to restore the normal values. After fasting, both glucose infusion (either intragastric or intraperitoneal) and $\mathrm{HC}$ feeding (refeeding) were able to restore the normal hepatic GK activities in rats ${ }^{(38,39)}$. Thus, intragastric glucose infusion is able to restore basal GK activities in only $4 \mathrm{~h}^{(40)}$.

In the absence of specific nutritional studies, maybe the most interesting article published so far concerning the nutritional regulation of GKRP is that of Chu et al. ${ }^{(64)}$. In this study, rats were intraduodenally infused with glucose (initial bolus of $500 \mathrm{mg} / \mathrm{kg}$ and then $28 \mathrm{mg} / \mathrm{kg}$ per min). The authors showed that the translocation of GK from the nucleus to the cytoplasm is quite fast (20-30 $\mathrm{min}$ ), explaining the switch in net hepatic glucose balance from output to uptake in response to glucose ingestion. Similarly, GK translocation in the liver in response to hyperglycaemia and hyperinsulinaemia was impaired in Zucker rats ${ }^{(65)}$. Interestingly and unlike GK, GKRP mRNA is induced by high glucose concentrations but not by insulin ${ }^{(66)}$. Toyoda et al. ${ }^{(67)}$ also showed that the GKGKRP complex was disrupted after the oral administration of either glucose (solution $20 \%$ ), fructose (solution $2.5 \%$ ) or glucose plus fructose to $24 \mathrm{~h}$ fasted rats, with a concomitant increase in glucose phosphorylation. This is in accordance with the data of Watford ${ }^{(68)}$ showing that small amounts of fructose-1-phosphate, in the presence of relatively high glucose levels, markedly stimulate GK through a novel mechanism of regulation involving dissociation from a regulatory protein and translocation from the nucleus into the cytosol. Nevertheless, this beneficial effect of fructose on liver glucose uptake does not persist during chronic nutrition (as in total parenteral nutrition) $)^{(69)}$ 
However, this effect is not common to all mammalian species. For example, pigs fed a high-fructose diet (40\% sucrose) exhibited lower GK activities than in the control group (1.23 v. $2.3 \mu \mathrm{mol}$ hexose phosphorylated/g tissue) $4 \mathrm{~h}$ after the last meal, suggesting that GK would be less induced in the presence of fructose, showing in that case a high specificity for dietary glucose ${ }^{(70)}$.

A few studies dealt with the developmental regulation of hepatic GK. In general, evidence shows that activity in newborns is lower than in adults ${ }^{(71)}$. In the rat, GK activity is detected for the first time $16 \mathrm{~d}$ after birth, with activities equivalent to those of the adult $10 \mathrm{~d}$ later ${ }^{(72)}$. Although both insulin and glucose are needed for the normal development of GK, their infusion before the sixteenth day has no effect. In contrast, if a HC diet is given only $2 \mathrm{~d}$ after the detection of GK, then the activity is inducible ${ }^{(73)}$, demonstrating that the neonatal rat liver is sensitive to nutrients present in the HC diet. In a more complete approach, Walker \& Eaton ${ }^{(74)}$ showed that normal GK development results from the nutritional transition between a HF diet (rat milk) and a HC solid diet (regular laboratory chow). In this set of experiments, GK activity was only inducible with a high-glucose $(60 \%)$ or high-dextrin $(60 \%)$ diet at day 18, only $2 \mathrm{~d}$ after the appearance of the enzyme activity in the liver. However, this ability to be induced can be abolished or severely retarded by diets without carbohydrates. The mRNA levels of the hepatic GK are not detected before the tenth day after birth, being detected from the fourteenth day, with an activity increasing up to 30 -fold in the next 2 weeks ${ }^{(61)}$. Moreover, if fasting-refeeding cycles are applied during development, then GK is resynthesised more rapidly than in normal pups. However, GK appearance can also be delayed if a carbohydrate-free diet is given at that stage of development.

Regulation of glucokinase by dietary carbohydrates: pancreas. GK activity in the pancreas is mainly controlled by glucose ${ }^{(50,75)}$, at least when cells are isolated in vitro or the organ maintained in culture, even if other studies did not detect any changes in GK activity after infusion of glucose and isolation of fresh islets ${ }^{(49)}$. However, GK protein levels did increase in vitro when pancreatic islets were incubated in the presence of high glucose concentrations $(30 \mathrm{~mm})$, but for a long period $(3-7 \mathrm{~d})^{(50)}$. At the molecular level, GK mRNA levels increased 3-fold in rats receiving an oral glucose load $(4 \mathrm{~g} / \mathrm{kg})$ only $1 \mathrm{~h}$ after the treatment ${ }^{(76)}$. It is worth mentioning that in the context of glucose regulation the role of GK interaction with the enzyme 6-phosphofructokinase-2-kinase/fructose-2,6-biphosphatase seems to be major in pancreatic tissue, given that such interaction increases in parallel with the glucose concentration in the culture medium ${ }^{(77)}$.

Concerning HC feeding, most of the information comes from the rodent model fed with simple sugars, like the high-fructose diet. Thus, quantities of dietary fructose between 10 and $60 \%$ for 3 weeks are able to enhance pancreatic GK activity and protein levels in rodents as part of the adaptative process of the islet glucose metabolism and glucose-induced insulin secretion ${ }^{(78)}$. In contrast, longer periods of feeding resulted in a blunted response due to the lipoglucotoxicity associated with the insulin resistance and dyslipidaemia in this nutritional model ${ }^{(79)}$. Finally, while GKRP is also expressed in the pancreas, no nutritional information is available ${ }^{(80)}$. GK has been also detected in pig islets at the protein level ${ }^{(81)}$, but unfortunately no information about its nutritional regulation is available.

Regulation of glucokinase by dietary proteins: liver. Consistent with their natural requirements, GK activity is maximal in rats fed a $65 \%$ dextrin diet. However, if carbohydrates are artificially substituted by protein $(90 \%$ protein instead of $20 \%$ ), GK activity is abnormally reduced ${ }^{(82)}$ (Table 2 and Fig. 4). This reduction is not visible after $4 \mathrm{~d}$ of feeding, but significant after $40 \mathrm{~d}$ of feeding ${ }^{(83)}$. Consistently, GK gene expression is also lower in HP-fed rats $(50 \% \text { milk protein })^{(84)}$. GK activity is lower in HP-fed rats than in HC-fed ones ${ }^{(38)}$.

The effects of individual amino acids have also been tested in a few studies. In rodents, branched-chain amino acids dose-dependently enhanced the mRNA levels of GK in rat liver and strongly increased GK mRNA expression and protein levels in HepG 2 cells in a glucose-dependent manner ${ }^{(85)}$, suggesting an improved hepatic glucose metabolism through an enhanced glucosensing system. In growing piglets fed with a carnitine-supplemented diet ( $0.5 \%)$ GK expression was induced 27-fold as compared with controls. This indicates that carnitine has a dramatic effect on glucose metabolism underlying one of the mechanisms involved in the health-related effects of carnitine, such as protection against neurodegeneration, mitochondrial decay, and oxidative stress as well as improvement in glucose tolerance and insulin sensitivity ${ }^{(86)}$. Weanling rats from dams maintained on a low-protein/HC diet displayed impaired insulin secretion associated with a lower $K_{\mathrm{m}}$ and protein levels for $\mathrm{GK}^{(87)}$. Similarly, the ability of hepatic GK to be induced during development (about $18 \mathrm{~d}$ after birth) can be abolished or severely retarded by diets high in protein $(75 \%)^{(74)}$.

Regulation of glucokinase by dietary proteins: pancreas. Animal models of protein malnutrition have provided important insights into the adaptive mechanisms involved in insulin secretion in malnutrition ${ }^{(88)}$. Mice supplemented with taurine ( $2 \%$ ) have higher insulin content, and insulin secretion from isolated islets accompanied by higher expression of genes required for glucose-stimulated insulin secretion including $\mathrm{GK}^{(89,90)}$.

Regulation of glucokinase by dietary fat: liver. In rats fed a HF (65\% fat) diet, hepatic GK activity is strongly reduced $^{(82)}$ or even not different from that observed in food-deprived animals $\left(75 \%\right.$ energy as fat) ${ }^{(83)}$ (Fig. 4 and Table 2). However, while in the early stages of continuous overnutrition in mice with a HF diet (32\% safflower-seed 
oil) hepatic GK is up-regulated ${ }^{(91)}$, chronic studies showed also that in the long term a fatty-acid-rich diet (cafeteria diet, $59 \%$ fat) reduces GK activity (-29\%) and protein levels in rats ${ }^{(92,93)}$. Additionally, higher GK activities than in the control group were reported in rats fed on a $\mathrm{HF}$ (25\% coconut oil)-high cholesterol (1 \%) diet, which has been associated with the needs of the liver to synthesise other substrates when glucose provided by the diet is low ${ }^{(94)}$.

In this sense, it is known that NEFA inhibit GK activity through allosteric binding ${ }^{(95)}$ and impair GK translocation in hepatocytes ${ }^{(96)}$. The effect of fatty acids depends on their nature. In the rat, GK mRNA increases when MUFA (10 \% of triolein) is added to a carbohydrate-enriched diet. However, if this fatty acid is replaced by PUFA (menhaden oil), the induction of GK mRNA is decreased by 60 to $70 \%{ }^{(97)}$. In vivo NEFA induce hepatic insulin resistance, probably due to an impairment of the ability of insulin to increase glucose cycling (through GK) and in vivo GK activity (for a review, see Lam et al. ${ }^{(98)}$ ). In this sense, in the HF diet-induced obese mice, decreased levels of the hepatic sirtuin (silent mating type information regulation 2 homologue 1; SIRT1), AMP-protein kinase $\alpha$ (AMPK $\alpha)$ and GK-3 $\beta$ proteins were described in comparison with the lean controls and were associated with steatosis, oxidative stress and inflammation ${ }^{(93)}$.

The ability of hepatic GK to be induced during development (about $18 \mathrm{~d}$ after birth) can be abolished or severely retarded by diets high in fat $(25 \%)^{(74)}$.

In human subjects, variability at the GKRP gene locus (LIPGENE study) showed that $n$-3 PUFA levels were associated with the degree of insulin resistance and plasma concentrations of C-reactive protein ${ }^{(99)}$. This suggests that a recommendation to increase $n-3$ PUFA could have an even more beneficial effect on insulin resistance and inflammatory markers only among metabolic syndrome patients carrying the $\mathrm{C} / \mathrm{C}$ genotype.

Regulation of glucokinase by dietary fat: pancreas. Kim et al. ${ }^{(100)}$ demonstrated that pancreatic GK is nutritionally regulated by dietary lipids. When feeding rats with a HF diet ( $40 \%$ fat) they observed a $50 \%$ reduction in GK mRNA levels and insulin secretion in comparison with the group fed the control diet ( $\mathrm{HC} /$ low fat). This suggests that the deleterious effect of a HF diet on glucose homeostasis could be based on a direct impact on pancreatic GK. Further support for this deleterious effect of dietary lipids is found in the study of Gremlich et $a l^{(101)}$ in which elevated fatty acid levels decrease the mRNA and protein levels of GK and insulin secretion in an in vitro rat pancreatic model.

The powerful effect of early nutrition on pancreatic GK and later $\beta$-cell functionality has been further confirmed using HF diets. Thus, weanlings from dams fed on a HF diet throughout both gestation and lactation have reduced GK mRNA and protein expression ${ }^{(102-104)}$.
Regulation of glucokinase by feeding-related hormones. Glucokinase in the diabetic state and other metabolicrelated disorders: liver. The first evidence of insulin regulating GK activity came from experiments in alloxan-diabetic rats, where insulin levels are almost undetectable. Thus, hepatic GK activity in diabetic rats is much lower than in normal rats ${ }^{(36,37)}$ and if insulin is administrated to diabetic-induced alloxan rats then GK activity is recovered and normal levels are achieved between 16 and $24 \mathrm{~h}$ of infusion ${ }^{(40)}$. Consistent with this, insulin administration has been shown to increase GK activity in rats, either acutely $^{(39)}$ or chronically (up to $14 \mathrm{~d}$ ) ${ }^{(105)}$.

In contrast to this, although GK mRNA levels recover from the diabetic state when insulin is administrated ${ }^{(43)}$, the kinetics of the mRNA levels was not equivalent, as higher GK expression has been found only $1 \mathrm{~h}$ after stimulation, with a maximum level $8 \mathrm{~h}$ after. In comparison, in in vitro studies, the mRNA levels of GK were rapidly increased, with the maximum levels observed between 4 and $8 \mathrm{~h}$ after insulin stimulation, which was independent of the glucose concentration in the medium ${ }^{(106)}$. Furthermore, the effect of insulin on GK was prevented by the addition of glucagon.

Hepatic GKRP quantity increases with insulin and decreases in the diabetic state ${ }^{(45)}$, which is further supported by the fact that glucagon inhibits in vitro the GK translocation to the cytoplasm ${ }^{(25)}$.

A recent study also suggests that the impaired inhibition of hepatic glucose production and increased glucose uptake in the liver of hyperglycaemic Zucker rats could be due to a failure of GK to be released from the GKGKRP complex ${ }^{(107)}$.

The relationship between human GK and insulin was first evident from the study of hepatic activity in diabetic patients, in which GK can be depressed $50 \%$ when compared with a healthy volunteer ${ }^{(63)}$. Further data confirm this, as the hyperinsulinaemia observed at certain stages of the diabetic condition is also able to actually increase GK activity in human subjects ${ }^{(108)}$. The confirmation of an insulin-sensitive GK in the human liver came from the studies by Iynedjian et al. ${ }^{(109)}$ using hepatocytes isolated from fasted human subjects, where GK activity and expression are strongly up-regulated, with a peak of induction $8 \mathrm{~h}$ after stimulation by insulin. Consistent with this, the addition of glucagon to the medium abolishes the action of insulin, highlighting the inhibitory effect of this hormone on human GK.

A very recent paper has shown that liver GK gene expression (in the fasting state) is associated with de novo lipogenesis markers and hepatic TAG content in the human liver, suggesting that GK activity may induce fatty liver and its metabolic and hepatic consequences in humans ${ }^{(110)}$.

Regulation of glucokinase by feeding-related hormones. Glucokinase in the diabetic state and other metabolicrelated disorders: pancreas. At least two characteristics 
differentiate hepatic and pancreatic GK, including that fact that the $\beta$-cell-specific promoter does not show a dramatic nutritional regulation by insulin and glucagon, and that glucose rather than insulin (as occurs in the liver) acts as its major regulator.

Among the diabetic and obesity animal models it is worth mentioning that in the sand rat (Psammomys obesus) after 1 week feeding with a high-energy diet, the pancreatic $\beta$-cell volume was reduced by one-third in hyperglyaemic animals. Insulin and GK immunostaining in the cytoplasm of the pancreatic $\beta$-cells were reduced by more than $50 \%$. After 3 weeks of high-energy diet feeding, all changes observed after 1 week were even more pronounced, with reductions in the range of $70-95 \%$. For all changes observed, there was a significant correlation with the increase in blood glucose concentration. Thus, increasing glycaemia appears to be the factor responsible for the deterioration of the pancreatic $\beta$-cell function and the resulting loss of the insulin-secretory capacity in Psammomys. The final result of this development is an irreversible diabetic state due to the feeding of the high-energy diet characterised by muscle insulin resistance and the inability of insulin to activate insulin signalling ${ }^{(111)}$.

Another model of GK-related diabetes developed in recent years is the double (liver and pancreas) mutants for $\mathrm{gk}^{\mathrm{del} / \mathrm{wt}}$ that show a reduced insulin secretion in response to glucose. The impaired glucose tolerance, and compensatory hyperinsulinaemia observed in response to a HF diet, seen in the $\mathrm{gk}^{\mathrm{del} / \mathrm{wt}}$ mice is similar to the phenotype recently reported in a HF-fed $\beta$-cell-specific $\mathrm{gk}^{\mathrm{del} / \mathrm{wt}}$ mouse strain ${ }^{(112)}$, suggesting that $\beta$-cells and not hepatic GK status may be the driver in the development of diabetes in these mice.

In humans, the impact of GK on metabolic-related diseases is significant, given that even minor changes in this enzyme would result in major changes in glucose homeostasis. Spontaneous mutations of the GK gene are manifested in a wide range of pathologies of glucose homeostasis, including hypoglycaemias, milder forms of persistent hyperinsulinaemic hypoglycaemia of infancy, borderline and mild hyperglycaemias of maturity-onset diabetes of the young type 2 (MODY2), and lifethreatening permanent neonatal diabetes mellitus requiring intensive and lifelong insulin therapy (for a review, see Matschinsky ${ }^{(6)}$ ). Similarly, several mutations in the GKRP gene have been associated with metabolic disorders, including liver fat accumulation in Hispanics on a highsugar diet ${ }^{(113)}$ and postprandial TAG on whole-grain intake ${ }^{(114)}$. GK mRNA levels in human diabetic pancreatic tissue is $50 \%$ lower than in healthy controls, which could be associated with the defect in insulin secretion in these patients ${ }^{(115)}$. The low activities of hepatic GK of untreated diabetic patients were restored to normal values by treatment with insulin or tolbutamide.
A direct effect of leucine on pancreatic GK has recently been reported in rat islets and type 2 diabetic human islets. Leucine culture for $2 \mathrm{~d}$ increased glucose-induced cytosolic $\mathrm{Ca}^{2+}$ elevation, ATP level, and insulin secretion as well as GK mRNA and protein levels. The increase in GK mRNA levels occurred as early as day 1 and lasted through to 1 week $^{(116)}$

As stated before, GK is also expressed in the pancreatic $\alpha$-cell, where it works as the limiting step for further glucose metabolism ${ }^{(117)}$. Given that glucagon production is inhibited by glucose, the fact that $\alpha$-cells express this protein could suggest that in the postprandial period GK may mediate glucose-inhibited glucagon production. However, this hypothesis needs to be explored further.

\section{Carbohydrate-independent mammalian species}

Glucokinase in carnivorous species: the example of the cat. During its evolutionary development the cat has adapted to a diet high in protein (about $54 \%$ of DM) and low in carbohydrates (about $8 \%$ of DM), directly linked to its natural diet consisting of animal prey ${ }^{(118)}$. In response to these dietary habits, when compared with omnivorous species (such as rodents or humans), cats have lower activities of carbohydrate digestive enzymes in the gastrointestinal tract, slower glucose incorporation rate into glycogen and elongated glucose elimination time in the glucose tolerance test ${ }^{(119)}$. These facts imply that the cat as a carnivorous animal is not well adapted to readily metabolise large glucose loads ${ }^{(120)}$. However, on the basis of all these facts, no dietary requirement for carbohydrates has been established for cats ${ }^{(121)}$. On the other hand, commercial cat foods often contain considerable amounts of carbohydrates, mainly as $\operatorname{starch}^{(122)}$. According to the carnivore connection theory of Brand Miller and Colagiuri ${ }^{(123,124)}$, an unnaturally high intake of carbohydrates in carnivores - especially carbohydrates with a high glycaemic index like simple sugars - may contribute to the development of diabetes mellitus. This could certainly be the case with domestic cats ${ }^{(119,122)}$. Cats have a very low functional GK with no capacity to be inducible by dietary carbohydrates, which associated with a minimal activity of hepatic glycogen synthase makes felines unable to rapidly minimise blood glucose after a HC meal. Thus, additional starch in the diet that is not stored as muscle glycogen or used for energy is stored as fat with the associated risk of obesity and insulin resistance. As stated above, cats are strict carnivores and considered to be deficient in hepatic GK based on their low GK expression and activity $^{(125-127)}$, which has been proposed as the cause of feline diabetes ${ }^{(126)}$. Paradoxically, the presence of GKRP in the liver of cats has not been detected, which discards the hypothesis of a low GK activity caused by its sequestration by the regulatory protein ${ }^{(45,128)}$. However, the existence of high HK activities and gluconeogenic enzymes in the feline liver seems to point to a different strategy, 
where low GK activity would be compensated by HK and the liver would be oriented to glucose production and export rather than glucose use, which is coherent with the nutritional profile of cats ${ }^{(129)}$. Given the nature of strict carnivores, the lack of GK in the feline liver has been traditionally considered as a natural feature of their nutritional condition rather than a metabolic defect ${ }^{(128)}$. Could it be then that the lack of hepatic GK acts as a 'carnivorous marker'? The answer is not clear given that other carnivorous species do have GK activity in the liver, including several fish species (see the 'Glucokinase in fish' section). In this sense, the GK observed in fish is often inducible by the presence of carbohydrates in the diet, even if they are not natural ingredients in carnivorous diets. As a matter of fact, most of the studies with cats have been made with fasted cats, even if they were fed with high proportions of carbohydrates in the diet. Given that the ability of GK to be induced by dietary carbohydrates is still unknown in the cat liver, then the performance of postprandial studies would be valuable. The main consequence of this putative lack of adaptative GK in the cat liver is that cats have a very poor control of glycaemia following a glucose load. This would result in a more persistent hyperglycaemia and slower glucose clearance than in other comparable mammals, like dogs ${ }^{(130)}$. Given that the glycogen-storage pathway is also very low in the cat ${ }^{(131)}$, then carbohydrates will be stored as lipids through de novo lipogenesis with the consistent associated pathophysiological complications, diabetes included $^{(122)}$.

In contrast to the situation observed in the liver, nutrient-sensing machinery seems to be present in feline pancreatic tissue, where the activity and expression of GK are comparable with those of other mammalian species $^{(127)}$.

Glucokinase in carnivorous species: the example of the dog. Very little information about dog (Canis familiaris) GK is available in the literature. For instance, most of the studies have been conducted using fasted animals, in which GK activity and expression have been characterised $^{(126)}$. The earlier studies showed that GK could play a role from a nutritional point of view, given that as in other species, dogs have an adaptative $\mathrm{GK}^{(132)}$ that seems to be regulated by insulin. This conclusion came from studies with diabetic dogs, which have $50 \%$ less GK activity in the liver than normal dogs ${ }^{(133)}$. More similarities are also shared with other mammalian species including the possible interaction with a regulatory protein, given that infused fructose $(1.7-6.7 \mu \mathrm{mol} / \mathrm{kg}$ per $\mathrm{min})$ is able to release GK from the binding with its regulatory protein, showing that the translocation of GK is a major determinant of hepatic glucose metabolism in dogs ${ }^{(134)}$. GK is also expressed in the dog pancreas. Finally, it is worth mentioning that more work is still needed regarding the characterisation of GK activity in dogs, given that some inconsistencies remain visible. Thus, the earliest studies reported quite high activity of hepatic GK, about $45 \mathrm{mU} / \mathrm{mg}$ protein in the fasted state. However, more recent studies do not agree with these results, and situate the GK activity in two different ranges: either about 10 $\mathrm{mU} / \mathrm{mg}$ protein $^{(126)}$ or $10-15 \mu \mathrm{U} / \mathrm{mg}$ protein ${ }^{(135)}$. While these differences are probably related to the experimental conditions rather than to the activity assessing method, further studies should be developed in order to better characterise this enzyme in the dog. At the nutritional level, very little is known in dogs. Recently, Coate et al. ${ }^{(136)}$ showed that in normal dogs GK activity increases in response to a meal, while in HF/high-fructose-fed dogs the GK protein content and activity are significantly reduced, resulting also in impaired net hepatic glucose uptake and glycogen storage ${ }^{(129)}$. Similarly, 4 weeks of a HF/high-fructose-diet feeding, a diet inducing glucose intolerance, markedly reduced GK protein content and GK activity in vivo in dogs, leading to impaired hepatic glucose uptake and postprandial hyperglycaemia ${ }^{(129,137)}$.

Glucokinase in ruminants. In contrast to singlestomached animals, in ruminants only small amounts of glucose are absorbed and transported from the gastrointestinal tract to the liver. Micro-organisms in the rumen ferment carbohydrates to the volatile fatty acids acetate, propionate and butyrate and these largely replace glucose as the main metabolic fuel of the tissues in the fed condition. As a result, blood glucose concentrations in cattle are significantly lower than in dogs, ranging between $2.4-4.5 \mathrm{~mm}$ in sheep and $2.3-4.2 \mathrm{~mm}$ in cattle $(138,139)$. The insulin-secretory response in ruminants also differs from that in non-ruminants, plasma propionate being a more potent stimulus for insulin release in ruminants ${ }^{(140)}$. Since no or very little glucose passes through the liver, the activity of the enzyme necessary for glucose phosphorylation (hepatic GK) is very low ${ }^{(141,142)}$. The very little free glucose that is normally absorbed by the ruminant intestinal tract does not allow the induction of this hepatic enzyme. On the other hand, the reliance of ruminants on fatty acids, especially volatile fatty acids, makes glucose an unattractive candidate as a primary fuel, also taking into account that the lack of hepatic GK may represent a metabolic advantage considering the continual need for gluconeogenesis in ruminants.

GK has been described to be present in several other mammalian species (revised by Cardenas $^{(8)}$ ) (Table 1). Among those species of special interest, it is worth mentioning that GK has not been detected in the liver of ruminants like dairy cows ${ }^{(142)}$. However, once more, the experimental design could be critical in order to detect this enzyme activity. Thus, while on this occasion cows were unfasted, no information about the exact postprandial period is offered. Moreover, cows were fed on a low-carbohydrate diet, which certainly needs to be explored more deeply. GK gene expression has been reported in the liver of offspring sheep at 1 year of age. 
It was increased in obese sheep as compared with lean sheep, but maternal diet restriction had no influence on the stimulatory effect of obesity on the GK gene ${ }^{(143)}$. Finally, the possibility of the expression of a fetal GK on ruminants has not been explored yet. Given that possible episodes of hyperglycaemia can exist during the nutritional transitions associated with animal development, further studies on this subject could be of interest.

\section{Glucokinase in birds}

Concerning birds, very little is known in comparison with mammals, and only a few species have been approached so far (Table 1). Among them, $72 \%$ of the published papers have focused on the chicken GK, the only species for which a partially exploitable GK sequence is available. The rest of the species are anecdotally represented, yet, very interestingly, species from different nutritional habits have been studied.

GK studies related in the present paper concern principally two granivorous domesticated species (chicken and duck) and a carnivorous wild species (owl) (Table 1).

\section{Peculiarities of glucose metabolism in avian species}

Birds develop adaptive mechanisms ensuring them an active energy metabolism characterised by a high basal temperature and glycaemia $\left(42^{\circ} \mathrm{C}\right.$ and $\left.11 \mathrm{~mm}\right)$. In spite of the high plasma glucose level, less evidence (see Scanes \& Braun ${ }^{(144)}$ ) supports close consistency in the control of metabolism in wild and domesticated birds, some species being more tolerant than others as revealed by glucose tolerance tests. The ability of birds to maintain and tolerate comparatively high plasma glucose concentrations appears to have evolved independently of other vertebrate groups ${ }^{(145)}$. The basis for the relatively high glucose levels in birds is still unknown. All carbohydrate metabolic pathways studied in mammals appear to operate in birds; they are merely observed in different proportions. For instance, there is a quick transition to gluconeogenesis in granivorous birds because of their small glycogen stores and high metabolic rates. Carnivorous birds demonstrate continuous gluconeogenesis from amino acids in both the fed and the fasted state, enabling meat-eating species to use a meal-eating schedule ${ }^{(146)}$. Despite significant research focus on glucose metabolism in poultry and to a smaller extent in wild birds (for recent reviews, see Braun \& Sweazea ${ }^{(147)}$ and Scanes ${ }^{(148)}$ ), certain fields have long been debated such as the existence of GK in avian species $^{(1)}$, or remain still enigmatic including the stillundefined nature of GLUT in avian muscle and fat tissue $^{(149)}$. These fields covering two limiting steps in peripheral glucose utilisation may, however, be a key to further understanding of the peculiarities of glucose homeostasis in avian species. Data concerning avian GK (mainly domestic birds) are further developed.

\section{Characterisation of glucokinase at the biochemical and} molecular level in avian species

Liver glucokinase activity. The presence of GK has long been controversial in avian species. Studies involved only liver GK activity and led to divergent results, mostly because of methodological difficulties in differentiating GK activity from other HK activities (Table 1). The methods currently used to measure GK activity in the 20000 to $100000 \mathrm{~g}$ supernatant fraction from liver extracts according to methods used in mammals ${ }^{(37)}$ have failed to detect a GK-like activity in avian species and its induction by a carbohydrate- or glucose-enriched meal (for a review, see Berradi et al. $\left.{ }^{(150)}\right)$. This has long precluded establishing the presence of a typical GK in avian carbohydrate metabolism $^{(1,151,152)}$. From a comparative physiological point of view this was a relevant and interesting question because GK plays an important role in mammalian glucose homeostasis and because avian species present several specific characteristics regarding glucose metabolism (see above). Two different extraction procedures ${ }^{(153,154)}$ made it possible to measure higher glucose phosphorylation at 100 mm-glucose $(\mathrm{H})$ and at $0.5 \mathrm{~mm}$-glucose $(\mathrm{L})$, with in both cases a $\mathrm{H} / \mathrm{L}$ value higher than 1.5 accepted as a preliminary suggestion of GK-like activity ${ }^{(153,155)}$. This is not sufficient, however, to prove the presence of GK, as $\mathrm{N}$-acetylglucosamine kinase (EC 2.7.1.59) can also phosphorylate glucose with low affinity. Precaution is thus needed for avoiding confusion between GK and $N$-acetylglucosamine kinase, such as verifying that the enzyme is competitively inhibited by $N$-acetylglucosamine ${ }^{(156)}$ or using additional criteria. Wals \& Katz ${ }^{(154)}$ identified GK-like activities in chicken (Gallus gallus) and Japanese quail (Coturnix japonica) liver extracts in fractions (1000 $\boldsymbol{g}$ and $27000 \boldsymbol{g}$ pellets) that were discarded by previous investigators. Klandorf et $a l .{ }^{(157)}$ further confirmed the presence of a GK-like enzyme in chicken liver extracts and showed equal distribution in the soluble and particulate fractions. A GK activity detected in $1000 \boldsymbol{g}$ pellets suggested that avian GK was present in the nuclear fraction. Berradi et al. ${ }^{(150)}$ also reported GK-like activity in soluble and particulate fractions of duck liver extracts. It was, on the other hand, possible to measure a soluble GK-like activity in the supernatant fraction of crude liver homogenates (900 $\boldsymbol{g}$ supernatant fraction) from the chicken and duck as described by Panserat $e t a l .{ }^{(158)}$. This method first reported for Atlantic salmon (Salmo salar) ${ }^{(153)}$ is commonly used to measure GK activity in fish species. GK-like activity measured in crude liver homogenates from fed chickens presented a high apparent half-saturating concentration of glucose of $8.6 \mathrm{~mm}^{(159)}$. In addition, $N$-acetyl-D-glucosamine, a known inhibitor of GK activity in mammals, significantly inhibited chicken GK activity by increasing the apparent $K_{\mathrm{m}}$ for glucose $^{(160)}$, which confirmed specificity of GK activity measurement. In addition, changes in GK kinetic parameters in response to GK activator (GKA) provide 
unequivocal evidence for the presence of a functional GK in chicken liver, most probably very similar in its structure and activity to those of mammalian $\mathrm{GK}^{(161)}$. Immunological and physiological studies further support that GK activities can be measured.

Comparison of glucokinase-like activity levels. It is difficult to compare GK activities of various species measured under different experimental conditions, media and techniques. However, some comparative studies carried out by the same author or using the same technique are available (Table 1). These studies suggest that GK activity is lower in the liver of avian species than in that of various mammals or fish species. Using a radiochemical method in the presence of glucose-6-phosphate as an inhibitor of low- $K_{m}$ HK, Stanley et al. ${ }^{(41)}$ reported three to ten times lower GK activities (U/g liver; nutritional state not defined) in the $100000 \boldsymbol{g}$ supernatant fraction of various avian species (chickens, pigeons and ducks) than in mammals (rats, mice and human subjects). GK activities reported by Myers \& Klasing (U/mg protein) were 100 times weaker in the liver of the chicken or owl (Tyto alba) than in the rat in this same $100000 \mathbf{g}$ supernatant fraction $^{(162)}$. When compared with fish species in the fed state, liver GK activity (U/mg protein) measured in the $10000 \boldsymbol{g}$ supernatant fraction was weaker in the chicken (standard diet, $35 \%$ carbohydrates) than in the rat (standard rodent chow, $60 \%$ carbohydrate) or the fish (10\% carbohydrate) $^{(47)}$. GK activity (U/mg protein) measured in the $900 \boldsymbol{g}$ supernatant fraction from chicken liver ${ }^{(163)}$ was similar to those of common carp (Cyprinus carpio) and gilthead sea bream (Sparus aurata) but were three to six times lower than that of rainbow trout $(24 \mathrm{~h}$ after meal, $>20 \%$ starch) ${ }^{(164)}$ (see Table 1). At the moment, there is no hypothesis for the low GK activities in the liver of chickens and ducks as well as in those of some fish.

Chicken-duck comparison. GK-like activity was reported in the liver of 15 -week-old overfasted mule ducks and 5-week-old overfasted broiler chickens ${ }^{(160)}$. In this study, liver GK activities were higher in ducks than in broilers (chicken diet $37 \%$ carbohydrates/duck diet 45 $\%$ carbohydrates). The difference may be linked to age or body weight. However, a species-related difference is possible and may be a characteristic of avian species susceptible to hepatic steatosis, such as Muscovy ducks (Cairina moschata) or Landes geese (Anser anser) ${ }^{(165,166)}$. Moreover, in the absence of overfeeding, fatty acid synthase activity of duckling livers was 10-fold higher than that of chicken livers ${ }^{(167)}$. The molecular basis for the high incorporation rate of glucose into fatty acids and the high level of lipogenic enzymes may involve GK, as suggested by the high level of GK $(1.76 v .0 .88 \mathrm{mU} / \mathrm{mg}$ protein) and by the GK:HK ratio (GK:HK $=3.2 v .1 \cdot 01)$, respectively, observed in fasted ducks compared with fasted chickens ${ }^{(160)}$.

Chicken-owl comparison. In the owl, a carnivorous bird species that consumes a diet consisting almost exclusively of animal prey, GK-like activity is six times lower than in the chicken ${ }^{(162)}$. Chickens and barn owls have large differences in the shapes of their glucose tolerance curves after either an oral $(22.2 \mathrm{mmol}$ glucose $/ \mathrm{kg}$ body weight in $10 \mathrm{ml}$ by oral administration) or intravenous glucose $(5 \mathrm{ml} / \mathrm{kg}$ body weight of $1.1 \mathrm{M})$ challenge. Very low liver GK activity in barn owls may be one possible explanation for these large differences in rates of glucose clearance ${ }^{(162)}$. Similarly, the lack of liver GK activity reported in cats (strict carnivorous mammal species) is believed to contribute to the prolonged glucose elevation observed following a glucose challenge ${ }^{(130)}$.

Pancreas glucokinase. Preliminary tests performed in our laboratory ( $\mathrm{N}$ Rideau, unpublished results) showed the presence of GK-like activity in the particulate fraction of chicken pancreas obtained according to Wals \& $\mathrm{Katz}^{(154)}$ (the soluble fraction was not studied). A GK-like activity in the $900 \boldsymbol{g}$ supernatant fraction from chicken pancreas was, according to Tranulis et al. ${ }^{(153)}$, however, not detectable. It is possible that the enzyme links with some particulate fraction that protects it from degradation (in particular by pancreatic enzymes). However, isolated islets of Langerhans constitute a better medium of study than whole pancreas homogenates. In mammals indeed, GK activity is studied using isolated islets of Langerhans.

Liver and pancreatic glucokinase messenger RNA and protein. Developments in molecular biology techniques have confirmed the presence of the GK gene in chickens and ducks. A gene coding for GK has not yet been found in the chicken genome database (http://www. ensembl.org/Gallus_gallus/). It is, however, noteworthy that the chicken genome has not been fully sequenced to date. A chicken complementary DNA fragment exhibiting high homology with human GK (> 80 \%) was, however, sequenced $^{(163)}$ from chicken liver and pancreas (gi 148743499 (1326 bp mRNA) and gi 44888569 (751 bp mRNA), respectively). A physical radiation hybrid mapping in the chicken suggests that the GK gene is most probably located on GGA22, a not yet sequenced microchromosome ( $\mathrm{N}$ Rideau and $\mathrm{M}$ Morisson, personal communication cited in Nadaf et al. ${ }^{(168)}$ ). A predicted Gallus gallus GK (HK 4) $(G K)$ mRNA sequence present on chromosome 22 was recently reported in Genbank databases (gi: 363745396 , 1263 bp mRNA). A single fragment from mule duck liver (600 bp) was also obtained, purified, cloned and sequenced $^{(160)}$. Comparison of the deduced amino acid (a.a.) sequence of chicken (Q8JHA6_CHICK; a.a. 1-442) and human liver GK (a.a. 1-465) shows $83.9 \%$ identity and $90.1 \%$ similarity ${ }^{(161,169)}$. The deduced 'avian GK protein' presents no amino acid modification at the glucose or ATP binding sites ${ }^{(170)}$, at the allosteric activator site and hydrophobic surface for GKA ${ }^{(171)}$, at the GK regulator (GKR) binding site except N166(K) and L355(F) that participate in the binding of $\operatorname{GKRP}^{(172,173)}$. Looking for hyperglycaemic mutations (avian species have a high basal glucose level and they are relatively insensitive to 
glucose-induced insulin release), we find some mutations located on amino acids showing mutations associated with mild hyperglycaemias of maturity-onset diabetes of the young type 2 (MODY2) ${ }^{(174)}$ but no difference on hyperglycaemic mutations as indicated by Zelent et al. ${ }^{(16)}$. There is no mutation on amino acid-activating mutation sites $^{(175)}$.

Liver and pancreatic GK proteins were immunodetected using two different polyclonal antibodies directed against the C terminal part of human GK (C20: a.a. 445-465/ H88: a.a. $318-405)^{(150)}$. In the chicken, antibody H88 detected one band of expected molecular mass (50 kDa) in the liver and two bands close to $50 \mathrm{kDa}$ in the pancreas. This suggests that, as in mammals ${ }^{(1,176,177)}$, there may be a second immunoreactive isoform of this protein in chicken pancreas. In duck liver, both antibodies revealed one band at $50 \mathrm{kDa}$. Intensity of the signal varied in response to overfeeding but in opposing ways according to the GK antibody used. Two isoforms of GK that are both immunoreactive have been characterised in mammal livers, but the minor isoform lacks catalytic activity ${ }^{(5,176,177)}$. In duck liver, two isoforms of GK are present as in mammals. One of the isoforms increases in response to overfeeding, as observed in rat liver after refeeding ${ }^{(178)}$.

Nutritional regulation of avian hepatic glucokinase: glucokinase regulation in chickens. In standard conditions (ad libitum feeding), liver GK-like activity was 2.2 higher in the fed state (regular, diet containing $37 \%$ carbohydrates and $22 \%$ proteins) than in the $24 \mathrm{~h}$ fasted state, but GK mRNA expression and protein level did not differ between the fasted and fed states ${ }^{(159)}$. Nutritional regulation of GK was further shown in chickens previously trained to meal-feeding (same regular diet as above, $2 \mathrm{~h}$ meal per d) and submitted to different nutritional conditions $^{(163)}$. Also, $2 \mathrm{~h}$ of refeeding alone was ineffective in altering hepatic GK mRNA, protein or activity. However, when an acute oral carbohydrate load was imposed at the beginning of the meal, GK activity significantly increased at the end of the meal and up to at least $3 \mathrm{~h}$ after the end of the $2 \mathrm{~h}$ meal; liver GK mRNA and protein significantly increased $3 \mathrm{~h}$ after the end of the meal (2-fold). Chicken liver GK expression (mRNA and protein) and activity were therefore inducible by feeding a meal with acute oral administration of carbohydrate. However, even in these highly stimulatory conditions, liver GK activity remained relatively low in comparison with other species (Table 2 and Fig. 4). Meal-induced GK gene expression was delayed in chickens when compared with rodents where a significant increase in GK gene expression was reported as soon as 1 and $2 \mathrm{~h}$ after refeeding following fasting whereas GK activity increased later on ${ }^{(43,44,179-181)}$. It thus seems that there is not a temperature effect, which has been a problem when comparing the kinetics of fish and mammal GK activities.

Nutritional regulation of avian hepatic glucokinase: glucokinase regulation in ducks. Muscovy ducks and
Pekin ducks (Anas platyrbynchos) present different susceptibility to liver steatosis in response to HC overfeeding (about $600 \mathrm{~g}$ starch $/ \mathrm{kg}$ ). Muscovy ducks are able to produce a heavy fatty liver (about $500 \mathrm{~g}$ ) while the Pekin duck produces a small fatty liver (about $300 \mathrm{~g}$ ). After 14 overfeeding days, Pekin ducks exhibited higher liver GK than Muscovy ducks, suggesting a greater ability to use glucose consistent with lower glycaemia (respectively $8.83 v$. $10.44 \mathrm{~mm}$ ). Plasma levels of insulin did not differ between Pekin and Muscovy ducks. In spite of lower specific GK activity, activities of the main enzymes involved in lipogenesis from glucose indicated that hepatic synthesis of fatty acids was more efficient in Muscovy ducks than in Pekin ducks ${ }^{(182)}$. Greater glucose utilisation in Pekin ducks, associated with a lower capacity for lipid synthesis, suggests that glucose may be directed towards ATP-producing pathways rather than lipid synthesis or to storage under glycogen form. Liver glycogen level in Pekin ducks is in fact half that of Muscovy ducks after overfeeding (E Baeza personal communication)

Nutritional variations of GK activity were also reported in the soluble and particulate phase of chicken liver ${ }^{(157)}$ and duck liver ${ }^{(150)}$. Waltz \& Katz ${ }^{(154)}$ demonstrated for the first time in chickens that GK-like activity was present in the soluble and particulate fractions of liver extract. As described above, the particulate fraction is not clearly defined but involves cellular and nucleus membranes. Klandorf et al. ${ }^{(157)}$ demonstrated further that glucose plus insulin $(1 \mathrm{U} / \mathrm{kg}$ intramuscularly + oral glucose intubation $2.5 \mathrm{~g}$; pre-treatment $24 \mathrm{~h}, 12 \mathrm{~h}$ and $2 \mathrm{~h}$ before cervical dislocation and excision of the tissues) significantly increased both soluble and particulate GK activities in the chicken liver $v$. ad libitum-fed chickens. In ducks a striking modification in the distribution of GK-like activity between the soluble and particulate fractions was observed in response to overfeeding ${ }^{(150)}$. GK-like activity per mg protein was strikingly low in the soluble fraction from control ducks. It increased massively and significantly in response to overfeeding, reaching a level fourteen times higher than that in controls after $1 \mathrm{~d}$ of overfeeding. It declined during the subsequent stages but remained stable, with a five times higher level than controls. Overfeeding also increased the particulate fraction GK-like activity per mg protein but to a lesser extent, as activity only doubled as compared with controls ${ }^{(150)}$. Meal-induced GK translocation may thus occur in birds and contribute actively to glucose disposal during the whole overfeeding period. Hepatic lipogenesis remains very active until the end of the overfeeding period in the goose ${ }^{(166)}$.

\section{Glucokinase-regulatory protein in chickens}

Recently, Polakof et al. ${ }^{(47)}$ obtained evidence for the existence of a regulatory protein of GK (a GKR-like protein) in liver homogenates of vertebrates, such as fish (trout, goldfish (Carassius auratus) and carp) and a bird (chicken), 
where previous studies failed in the detection of both GK and GKR-like protein ${ }^{(45)}$. A GKR-like protein in the liver of those species presented a molecular weight $(68 \mathrm{kDa})$ and kinetic characteristics similar to those described in mammals; however, several of the biochemical properties of rainbow trout GKR-like protein were closer to the mammalian model whereas those of chicken protein were specific. The authors also compared the presence and properties of GKR-like protein in livers of different teleost species that exhibit different tolerances to glucose such as rainbow trout (intolerant) and goldfish and common carp (tolerant). The results showed that the most powerful GKR-like protein was found in the most intolerant species, whereas the inhibition exerted by GKR-like protein in tolerant species was closer to the chicken than to the rat.

What is the relationship between hepatic glucokinase, plasma glucose and insulin levels in birds? In mammals, liver GK is induced in response to a meal or following the administration of insulin (see above). One of the major roles of insulin in the liver is stimulation of the synthesis and activity of GK in mammals ${ }^{(183)}$. In the chicken and duck, nutritional variations of GK activity are linked to an increase in plasma glucose and insulin levels and to a very significant increase in liver relative weight $^{(150,159,163,182)}$ (Table 2 and Fig. 5).

Insulin dependency of liver GK (mRNA and protein) was clearly demonstrated after insulin immunoneutralisation in the chicken ${ }^{(169)}$. In this experiment, liver GK gene expression and protein decreased at $5 \mathrm{~h}$ following insulin privation or fasting. Large hyperglycaemia was induced by anti-insulin serum injection. Hyperglucagonaemia and low triiodothyronine were early hormonal perturbations observed in the absence of an insulin signal. This agrees with mammals, where glucagon and thyroid hormones, respectively, decrease and increase liver GK gene expression ${ }^{(29)}$. The decrease in liver GK mRNA and protein in fed chickens following insulin privation should decrease liver glucose utilisation and contribute to the development of marked hyperglycaemia. GK knockout mice display mild basal hyperglycaemia and exhibit a profound defect in glucose turnover ${ }^{(184)}$.

In contrast, oral administration of a GKA to ad libitumfed chickens induced a dose-dependent and large decrease in plasma glucose ${ }^{(161)}$. The GKA induced a 40-50\% decrease in plasma glucose level in fed chickens and a $13 \%$ decrease in fasted chickens. Even at $40 \mathrm{mg} / \mathrm{kg}$, i.e. the dose required to obtain the maximal hypoglycaemic effect, GKA did not induce a clear increase in plasma insulin levels early in the experiment. Within the same period of time (3-15 min), plasma glucagon levels did not change. In chickens GKA appears to act mostly if not exclusive by activating liver GK in the fed or fasted state, which contrasts with results obtained in mammals ${ }^{(185,186)}$. In the dog GK activation is able to enhance net hepatic glucose uptake in the absence of insulin secretion following somatostatin infusion ${ }^{(187)}$. It is quite possible that the same and still-unidentified steps that prevent nutrients to be insulinotropic in chicken endocrine pancreas ${ }^{(188)}$ also prevent GKA being insulinotropic in this species. Dupont et al. ${ }^{(189)}$ showed that the high basal glycaemia of avian species does not result from insulin resistance at the hepatic level, as observed in chickens. It can thus be
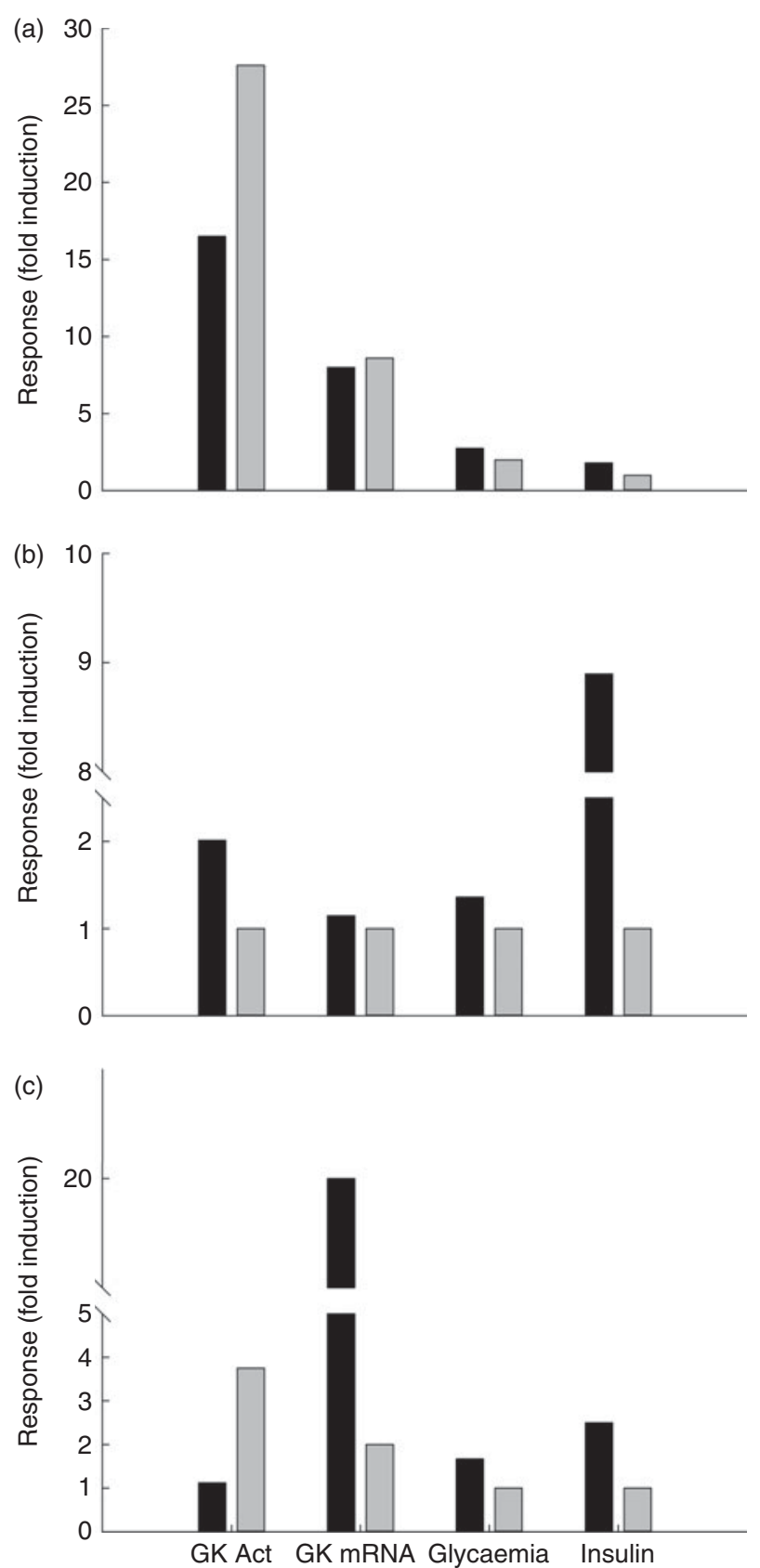

Fig. 5. Response of hepatic glucokinase (GK) activity (Act) and messenger RNA (mRNA) levels, and plasma glucose and insulin concentrations to a meal rich in carbohydrates in the rainbow trout (a), chicken (b) and rat (c). Data represent the fold-induction change of each parameter between 2 and 6 $\mathrm{h}$ after the meal when compared with the values in the fasted state or fed a carbohydrate-free diet (trout). The diet included 20, 37 and $67 \%$ of carbohydrates for trout, chicken and rat, respectively. Trout were reared at $18^{\circ} \mathrm{C}$. The values were obtained from Iritani et al. (rat) ${ }^{(44)}$, Polakof et al. (fish) ${ }^{(243,244)}$, Capilla et al. (fish) ${ }^{(211)}$ and Rideau et al. (birds) ${ }^{(163)}$. $\mathbf{0}, 6 \mathrm{~h}$ (trout), $3 \mathrm{~h}$ (chicken), $2 \mathrm{~h}$ (rat); $\square, 24 \mathrm{~h}$. 
hypothesised that the low liver GK activity reported above in avian liver ${ }^{(163)}$ may partly contribute to the high basal plasma glucose level of avian species decreasing acutely in response to GK activation

GKA administration to chickens also reduced food intake ${ }^{(161)}$. Infusion of glucose into the hepatic portal vein decreased food intake in a dose-dependent manner in chickens ${ }^{(190)}$. It has been hypothesised that an increase in hepatocyte metabolism following perfused glucose would generate a neuronal satiety signal to the hypothalamus. A contribution of the liver to the regulation of food intake is thus suggested byRideau et al. ${ }^{(161)}$, rather than a putative activation of the brain GK by GK activation.

\section{Glucokinase in fish}

Fish is a quite particular group regarding the study of GK. While this group does not represent a major interest for human studies (only $4 \%$ of the studies involved zebrafish), the characterisation of GK has been approached in several species, most of them (86\%) carnivores. This is of special interest, given that in the other groups carnivores are rarely represented and the study of GK in this particular (maybe unexpected) group could be key to understand better the evolution and function of this enzyme. In this sense, while $58 \%$ are mono-species (rainbow trout, Oncorbynchus mykiss), other fish such as carps or sea breams are quite well represented. From a phylogenic point of view, the most-clear group represents the cyprinids (omnivores), while salmonids and sparids (both carnivorous) appear quite far from each other.

Both reptiles and amphibians have been very rarely approached as models for GK studies, except for Xenopus, which was used for rodent and human studies. Other than this, GK activity has been characterised at the biochemical level in a few species (Table 1), while molecular information is just limited to Xenopus (Fig. 3).

No existence of glucokinase in fish: a (false) hypothesis to explain poor dietary carbohydrate use in carnivorous fish

Unlike mammals, glucose appears to be a minor energy fuel in fish ${ }^{(191-193)}$. Although many tissues (heart, brain and kidney) are highly glycolytic tissues, in the absence of dietary carbohydrates, protein and lipids are oxidised quickly and efficiently to provide the energy required to cover needs ${ }^{(193,194)}$. Thus, oral or intraperitoneal administration of glucose or consumption of food rich in digestible carbohydrates lead to the appearance of a prolonged postprandial hyperglycaemia in rainbow trout up to $17 \mathrm{~mm}$ over $24 \mathrm{~h}$ ('normal' glycaemia is about 4-5 $\mathrm{mm})^{(192,193,195,196)}$. Studies have shown that there are differences for glucose tolerance tests between fish species; between carnivorous salmonids (low tolerance) and omnivorous cyprinids (tolerant); between coldwater fish and warmwater fish ${ }^{(193,196)}$. This observation is really linked to the fact that fish are the largest group of vertebrates (25 000 species). In this section, we will try to give the name of the species in order to be more precise in our review.

Some authors proposed 20 years ago a hypothesis that could explain the poor glycaemic control observed in some teleosts: it was the inability of fish to efficiently phosphorylate glucose to glucose-6-phosphate, a reaction catalysed by the HK enzyme family. In fish, the high activities of enzymes such as low- $K_{\mathrm{m}}$ HK (mainly HK-I) have been described in tissues such as the heart, kidney and brain, but in other tissues (liver, muscle), the data have been less clear ${ }^{(196)}$. Three hypotheses have been advanced to explain the occurrence of postprandial hyperglycaemia in some species: (i) low glucose phosphorylation by HK in insulin-sensitive tissues such as white muscle (and a poor glucose transport); (ii) a lack of expression of inducible GK in the liver ${ }^{(196)}$; and (iii) in some species, the amino acids are recognised as molecules as effective as glucose itself to induce insulin secretion ${ }^{(191)}$. This could be explained by a lack of expression of GK in pancreatic $\beta$-cells. The absence of GK activity in the livers and pancreas of fish has been contradicted by many different studies from the 1990s up to now in many fish species; the discover of GK in fish is described in the following section.

\section{Characterisation of hepatic glucokinase at biochemical and molecular levels}

Proof of the existence of hepatic GK in fish was first described at the level of enzymic activities in the 1990s followed by molecular characterisation of GK mRNA in the 2000s. The first analysis and proof of existence of GK activities in the liver were described by Tranulis et al. ${ }^{(153)}$ and Borrebaek et al. ${ }^{(197)}$ in Atlantic salmon after partial purification of the enzyme: this enzyme had a low affinity for glucose, a molecular mass estimated at $50.7 \pm 0.6 \mathrm{kDa}$, displayed positive cooperativity with respect to glucose and was totally inhibited by a $N$-acetylglucosamine (a specific GK inhibitor) with a inhibitor constant $\left(K_{\mathrm{i}}\right)$ of $0 \cdot 28 \mathrm{~mm}$. The presence of hepatic GK was later confirmed at a biochemical level in different fish species such as rainbow trout, gilthead sea bream, European sea bass (Dicentrarchus labrax), perch (Perca fluviatilis) and common carp $^{(164,198-200)}$. In mammals, GK is regulated in vivo by a regulatory protein through a nucleus-to-cytoplasm translocation enhanced by fructose-1-phosphate and counteracted by fructose-6-phosphate; Polakof et al. ${ }^{\text {(47) }}$ obtained for the first time the presence of a regulatorylike protein in the liver of rainbow trout, goldfish and common carp, with molecular weight $(68 \mathrm{kDa})$ and kinetics characteristics similar to those described in mammals.

In parallel with these biochemical studies, there were many studies on molecular cloning of the full-length GK complementary DNA in rainbow trout, gilthead sea bream and common carp ${ }^{(158,198)}$. Compared with mam- 
mals, the amino acid deduced sequences were highly similar to those of mammals (more than $80 \%$ ), suggesting strongly the existence of GK genes in fish with GK-specific amino acid signatures (Fig. 3). An interesting study searched fish HK genes (mRNA) in zebrafish by BLAST (Basic Local Alignment Search Tool) analysis ${ }^{(201)}$; the authors determined their expression in liver, muscle, brain and heart; measured their response to fasting and glucose administration; and performed homology sequencing studies to glimpse their evolutionary history. The study also suggested strongly the presence of GK genes in fish.

\section{Nutritional regulation of hepatic glucokinase}

\section{Regulation of hepatic glucokinase by dietary} carbohydrates. As already explained, there is no need for dietary carbohydrates for many of the studied fish which are located at the high trophic levels (as predators, trophic level between 3 and 4). The induction of hepatic GK after feeding carbohydrates in these fish species, after controversies, has been definitely proved by different studies in distinct carnivorous fish; freshwater fish (such as rainbow trout) and marine fish (sea bass and sea bream $)^{(164,198,202-206)}$. In rainbow trout, the level of enzymic activities is equivalent to that found in mammals $(20 \mathrm{mU} / \mathrm{mg} \text { protein })^{(164,207,208)}$. Moreover, this induction of activity is mainly linked to the induction of GK gene expression in the liver. The increased GK gene expression in the liver of carnivorous fish appears after long-term feeding with carbohydrates but also after a single meal with carbohydrates, as shown in rainbow trout ${ }^{(204,209,210)}$ (Figs. 3 and 4). As expected, fasted fish have no more GK activities and gene expression. They seem to have no gradual regulation of $\mathrm{GK}$, but more an on-off system linked to the presence or the absence of the carbohydrates. However, the molecular mechanism of this regulation remains to be elucidated, representing one of the greatest challenges in the field. More surprisingly, the induction of GK activity by carbohydrates is lower in omnivorous fish known to utilise carbohydrates well, i.e. common carp $^{(164,211)}$, Indian carp $(\text { Catla catla })^{(212)}$, silver sea bream (Pagrus auratus) ${ }^{(213)}$, zebrafish (Danio rerio) ${ }^{(214)}$, tilapia (Oreochromis niloticus x O. aureus) ${ }^{(215)}$ and grass carp (Ctenopharyngodon idella) ${ }^{(216)}$. This suggests that induction of hepatic GK is not a limited factor to use dietary carbohydrates. GK regulation can depend also of the sources of carbohydrates; indeed, hepatic GK activities were higher in fish fed glucose and the maltose diets than those fed with dextrin and $\operatorname{starch}^{(217,218)}$. The induction of hepatic GK by dietary carbohydrates is very reactive and can increase and decrease very quickly; postprandial analysis of GK expression and activities describe perfectly the postprandial profile of GK after refeeding even with a single meal ${ }^{(209,210,219,220)}$ (Fig. 5). In another study, the response of the GK gene to dietary carbohydrates varied by sex; indeed, after increased dietary carbohydrate intake, male zebrafish up-regulated genes associated with oxidative metabolism while only female zebrafish upregulated genes associated with glucose phosphorylation (for example, GK) ${ }^{(214)}$. Finally, fish being poikilotherms, at high temperature, the induction of hepatic GK expression and activities in gilthead sea bream and European sea bass fed with carbohydrates is stronger ${ }^{(221-223)}$, showing interaction between nutrition and temperature in fish.

Regulation of hepatic glucokinase expression by dietary proteins and lipids. The effects of macronutrients other than carbohydrates on hepatic GK have also been studied in fish when investigating if dietary proteins or dietary lipids can play a role in hepatic GK regulation. In fish fed with carbohydrates, it has been shown that high levels of dietary proteins or dietary lipids are associated with a decrease of glucose homeostasis. However, the negative effect of high levels of proteins or lipids on glucose tolerance is not linked to a decrease in GK expression and activities (in contrast to the enzymes in gluconeogenesis and lipogenesis which are up- and down-regulated, respectively) ${ }^{(224-227)}$. Finally, the regulation in vivo by the quality of dietary lipids (different level of highly unsaturated fatty acids, i.e. DHA) and dietary proteins (different levels of target amino acids such as glutamate, alanine and aspartate) also did not seem to affect dramatically GK expression and activities ${ }^{(228,229)}$. All these data suggest that hepatic GK is mainly regulated by dietary carbohydrates also in (carnivorous) fish (Table 2).

Nutritional regulation of hepatic glucokinase expression in fish larvae. The nutritional metabolism at first feeding has been analysed also in fish larvae/alevins. In most fish species, there is a passage between endogenous feeding (using vitellus reserves, naturally poor in carbohydrates) to exogenous feeding after opening of the mouth. Indeed, and intriguingly, the first feeding induces the expression of GK even if the diets are without glucose ${ }^{(230)}$. Moreover, if the fish larvae/alevins are fed with carbohydrates, there is significantly higher GK gene expression, showing that the regulation of GK by levels of carbohydrates occurs very early in the life of fish such as common carp and rainbow trout ${ }^{(230,231)}$. The response of GK to nutrition occurs very early in the life of fish.

Particular case of glucokinase regulation by alternative diets recently developed for aquaculture. For the development of sustainable aquaculture, there is an urgent need for the development of alternative plant diets (composed of plant proteins and vegetable oils) in order to replace the usual ingredients of fish oil and fishmeal in inert diets ${ }^{(232)}$. Many of these diets are without carbohydrates even if they are plant-based diets. Globally and, as expected, due to the low level of carbohydrates in the new diets, no drastic differences concerning GK have been described between fish (rainbow trout, gilthead sea bream, Atlantic salmon) fed with the different diets ${ }^{(233-236)}$ 
Finally, the GK enzyme seems to be nutritionally regulated (mainly by carbohydrates) as in mammals. The following section will detail the nutritional factors (through nutrients directly or through nutritional hormones) that can regulate GK enzyme expression in fish.

Mechanisms of nutritional regulation of hepatic glucokinase in fish: insulin, glucose and amino acids. In order to better understand the molecular mechanisms for the regulation of hepatic GK in fish, some additional analysis have been performed using in vivo and in vitro approaches mainly in rainbow trout and gilthead sea bream. After intraperitoneal injection of glucose, we observed significant GK induction at the molecular level in rainbow trout ${ }^{(237,238)}$ On the other hand, injection of insulin in rainbow trout surprisingly reduced the level of GK gene expression in contrast to mammals and birds, even though insulin has a clear hypoglycaemic mammalian-type effect ${ }^{(217,237,238)}$. These data were confirmed using micro-osmotic pumps with insulin; the chronic infusion of insulin reduced also the level of GK mRNA ${ }^{(237)}$. Using rainbow trout hepatocytes, the same antagonist results of glucose and insulin on GK gene expression have been also shown. All these data strongly suggest that hepatic GK expression in rainbow trout is not insulin dependent but glucose dependent; these data are clearly different from what is observed in mammals and birds (see previous section). Hepatic GK in rainbow trout could thus be included in the category of glucose-responsive genes. Because insulin secretion is not dependent on the type of diet (diets without carbohydrates also induce insulin secretion), we can understand why hepatic GK is induced only in presence of carbohydrates in rainbow trout. However, data in fish can be discordant and GK gene expression in gilthead sea bream (also a carnivorous fish) seems to be insulin dependent. Indeed, in hepatocytes of gilthead sea bream, some transcriptional factors have been located in the promoters of GK genes and seem to be functional; the specificity protein Sp1, specificity protein Sp3 and sterol regulatory element-binding protein-1a (Srebp1a) play a role in the induction of GK expression by insulin ${ }^{(239,240)}$. In conclusion, further studies on mechanisms for GK regulation by nutrients are needed to have a better understanding of the function of GK in fish.

\section{Nutritional regulation of extra-hepatic glucokinase (intestine, pancreas and hypothalamus) in fish}

GK is expressed in extrahepatic tissues in fish as in mammals. The function of GK protein in these tissues is not to convert excess glucose to glycogen or lipids (through lipogenesis) as in the liver but more to act as a glucose sensor to help the organism regulate glucose homeostasis $^{(193)}$. Key to the maintenance of glucose homeostasis in animals is the existence of sensors located in different parts of the body that continuously monitor blood glucose concentration. The molecular basis for the glucose detection is located mainly in pancreatic $\beta$-cells and in neurons excited by glucose found in the septum, amygdale, striatum, cortex, hindbrain and hypothalamus. This is the same picture in fish (even those carnivorous) described below ${ }^{(193)}$. We will not detail here other factors than nutrients (such as leptin, ghrelin, days/night variation) that can also modify the glucosensing actors in fish (and GK) but are not directly linked to nutritional regulation (thus being out of the scoop of the present review).

Expression of glucokinase in $\beta$-pancreas of fish and its regulation by feeding. Several studies have demonstrated the presence of glucosensor actors in $\beta$-pancreatic cells in different fish species. The characterisation of a GK protein in fish was performed in the pancreas of fish almost at the same time as in the liver. Indeed, in halibut Brockmann bodies (i.e. masses of pancreatic endocrine cells in some fish species), GK activity was highlighted for the first time by Tranulis et al. ${ }^{(241)}$ using enzymic data: with increasing glucose concentrations, the enzyme activity showed a GK-like sigmoidal saturation curve. Moreover, $N$-acetylglucosamine inhibited the enzyme competitively against glucose with an inhibitor constant $\left(K_{\mathrm{i}}\right)$ of $0.26 \mathrm{~mm}$. The existence and induction of a GK enzyme in the pancreas have been described linked to the fasting-refeeding transition ${ }^{(207)}$. GK activities in the pancreas are up-regulated by the intake of carbohydrates or intraperitoneal glucose injection ${ }^{(208,242-244)}$. Moreover, pancreatic GK activities and gene expression (but to a smaller extent) are under the (positive) control of glucose $\mathrm{e}^{(208)}$, as in mammals. The key role of GK as a metabolic signal to initiate insulin secretion has been investigated using in vitro approaches $^{(245)}$. Even though all these data suggest strongly a key role played by pancreatic GK in insulin secretion in fish, there is for the moment no direct evidence linking changes in this enzyme with hormone secretion in fish.

Expression of glucokinase in brain (hypothalamus) and intestine and its regulation by feeding. Many of the studies of GK in the brain have been performed in rainbow trout by Soengas's team. First, GK protein has been localised in different areas of the brain in rainbow trout ${ }^{(47)}$ : GK activity, expression and immunoreactivity were found in the hypothalamus and hindbrain of rainbow trout where they were related to food intake regulation and glucose homeostasis. The activity and expression of GK were increased in the hypothalamus and hindbrain of rainbow trout in the presence of hyperglycaemia (after carbohydrate intake or glucose administration) ${ }^{(208,242)}$, confirming that GK in the brain can also be a glucose sensor in fish. This GK activation in the brain could be related to modulation of the decrease in food intake with hyperglycaemia in fish ${ }^{(207,242,243)}$, as in mammals. However, no direct evidence exists. Finally, GK in the brain can be very important for the counter-regulation of hypoglycaemia ${ }^{(246)}$ through vagal and sympathetic outflow to the level of glucose production in the liver. This relationship 
between GK in the brain and the regulation of hepatic glucose production needs further studies in fish.

Glucosensing capacities are important in gastrointestinal tract cells in mammals using the same actors as those described in the pancreas. GK transcripts have been detected in enterocytes and enteroendocrine cells ${ }^{(247)}$. These data together with the fact that GK gene expression and activities were enhanced in the midgut of hyperglycaemic trout constituted the first evidence for a glucosensing function in enteroendocrine cells of the gut of rainbow trout.

\section{Conclusions and perspectives}

Given the increasing epidemic of diabetes and other metabolic-related diseases in Western countries, an important part of the scientific community has focused its attention on GK, the gene of which has even been called the 'diabetic gene ${ }^{(4)}$. However, while the interest in activating GK using a pharmacological approach (the so-called $\mathrm{GKA}^{(248)}$ ) increases, information about the nutritional role and regulation of this enzyme remains paradoxically (taking into account the nutritional impact on diabetes and obesity incidence) almost unknown. In this sense, maybe the most relevant new information about human GK is the recent genome-wide association studies ${ }^{(99)}$, given that some of them have already reported polymorphisms and alleles concerning GK and GKRP that strongly suggest that these protein play a strong role in glucose homeostasis. Further, this opens the door to a new generation of nutritional interventions based on the idea that clusters exist in human populations regarding response to diet. This idea, linked to the new personalised nutrition programmes, should improve in the coming years our knowledge about the nutritional role of GK in humans. On the other hand, and based on the huge amount of data obtained from laboratory animal models (mostly rodents) we know today that the nutritional regulation of GK is of utmost importance. Thus, HF feeding in rodents results in an important reduction in the functionality of the enzyme at all the studied levels and in both the liver and pancreas. This leads in the liver to reduced glucose phosphorylation and capacity to store the glucose excess as glycogen with the concomitant associated glucose intolerance. At the pancreatic level, HF feeding reduces the expression of the enzyme and other components of the glucosensing system, resulting in impaired glucoseinduced insulin secretion. Unfortunately, no studies in human subjects have addressed this problem and we do not know the impact of HF consumption in the current human population on GK. The other major dietary actor on GK regulation is fructose. This pentose is known to play a role in the GK-GKRP interaction and, based on this, the first studies in rodents have shown that under low fructose intake the release of GK from the GKGKRP complex results in increased GK activity and hepatic glucose uptake. However, while this has also been demonstrated in human subjects in the very short term, longer studies do not support this idea. The deleterious effect of high fructose feeding in animal models, yet not totally demonstrated in human subjects, is well known today and given the high fructose consumption in the Western countries these days a more deep analysis of high dietary fructose intake on GK is strongly recommended. As a whole, taking into account the increased consumption of diets with high contents of fat and fructose the long-term impact of this kind of diet on human GK and its role in the loss of glucose tolerance certainly merit further studies.

Finally, the other area of interest concerning the nutritional regulation of $\mathrm{GK}$ is that of the species of interest for humans, including companion animals and livestock:

(1) Concerning the first group, cats are the most affected species, given that their current diets are too high in carbohydrates for this carnivorous species and that they have a very 'lazy' and non-abundant GK. In this case, the HC content seems to not be adapted to the nutritional nature of this species, which has been associated with a high prevalence of obesity and diabetes in domestic cats given the inability to clear properly the glucose excursions after a HC meal. Strategies to induce this enzyme in felines or more adapted diets seem to be the better ways to alleviate this problem.

(2) The other group of animals consists of the farm species. However, the approach does not seem to be the same for ruminant and single-stomached species, given that in the first case the reliance on glucose is minimal and then the absence or very low activity of GK would be justified. In the second case very little information is available, but in those studies in which a nutritional component was present it seems that the role of GK would be worth exploring. Without doubt, more studies are needed in mammalian species such as horses or pigs. In the fish group, it is puzzling and exciting that carnivorous fish fed naturally only with dietary proteins and dietary lipids and without carbohydrates have conserved the mammaliantype nutritional regulation of GK by carbohydrates (except for the insulin-dependent regulation). Because the GK enzyme is mainly known up to now to sense excess glucose in the pancreas and store excess glucose in the liver (after carbohydrate intake), the conservation of GK in carnivorous fish suggests that GK in these animals can play major roles in life probably not only linked to dietary glucose. Indeed, there are other GK-expressing cells of the body that include central nervous system neurons, enteroendocrine cells and the anterior pituitary. All these GK-positive cells also express a wide range of G-protein-coupled nutrient receptors (including the amino acid-sensitive $\mathrm{Ca}$ receptor, receptors for NEFA and for sweet taste); this colocalisation suggests that 
GK operates synergistically (or even permissively) with such nutrient receptors ${ }^{(7)}$. Further studies are thus needed to clarify the function of GK in carnivorous fish. Finally, knowledge relative to GK is much less developed in avian than in fish or mammalian species, mainly due to long-lasting controversies about the presence itself of GK. However, we know now that GK (mRNA, protein and activity) is present in the liver of some avian species and that it is an inducible enzyme as in mammals. GK mRNA and protein are also present in the chicken pancreas. Chicken and duck liver GK are insulin dependent (as in mammals but contrary to most fish species) and contribute to glucose storage (glycogen, lipids) or ATP synthesis as extensively described in mammals and fish. Liver GK activity reported in avian species is relatively low as compared with most fish or mammal species; GK activation strongly decreased plasma glucose, which suggests that low liver GK activity may be involved in the high plasma glucose levels that characterise birds. In addition, a role of GK in glucose intolerance is suggested in a carnivorous species (owl) compared with a granivorous one (chicken). Glucose intolerance is also observed in cats (strict carnivorous mammal species lacking GK), whereas induction of hepatic GK does not seem to be a limited factor to use dietary carbohydrates in fish species. Finally, many domains remain still unexplored in birds including the effects of proteins and lipids on liver GK enzyme and their interplay with carbohydrates in the diet, the developmental regulation of hepatic GK, the presence of extra-hepatic GK (intestine, pancreas and brain) and its nutritional regulation. Involvement of GK in the variations of plasma glucose levels observed under genetic and nutritional factors may also be a relevant question for poultry production.

\section{Acknowledgements}

The present review was supported by grants from the French National Institute for Agricultural Research (INRA-PHASE research department), the French National Research Agency (no. ANR-08-JCJC-0025), the 'Conseil Regional d'Aquitaine', the interprofessional committee of 'Foie gras', and the European Commission (Fisheries Agricultural and Agro-Industrial Research, Contract FAIR-no. CT95-0174; FAIR-no. QLK5-2000-30068, 'Perspectives of Plant Protein Use in Aquaculture' (PEPPA); and FAIR-no. Q5RS-2000-30058, 'Researching Alternatives to Fish Oils in Aquaculture' (RAFOA), and the contract no. 016249-2, 'Sustainable Aquafeeds to Maximise the Health Benefits of Farmed Fish for Consumers' (AQUAMAX)).

All the authors have contributed to the writing and the revision of the text and have approved the final version.

There are no conflicts of interest to declare

\section{References}

1. Cárdenas ML, Cornish-Bowden A \& Ureta T (1998) Evolution and regulatory role of the hexokinases. Biochim Biophys Acta 1401, 242-264.

2. Wilson JE (1995) Hexokinases. Rev Physiol Biochem Pharmacol 126, 65-198.

3. Printz RL, Magnuson MA \& Granner DK (1993) Mammalian glucokinase. Annu Rev Physiol 13, 463-496.

4. Iynedjian PB (2009) Molecular physiology of mammalian glucokinase. Cell Mol Life Sci 66, 27-42.

5. Cárdenas ML (1995) Glucokinase: its Regulation and Role in Liver Metabolism. Austin, TX: R.G. Landes Publishers.

6. Matschinsky FM (2009) Assessing the potential of glucokinase activators in diabetes therapy. Nat Rev Drug Discov 8, 399-416.

7. Matschinsky FM (2013) GKAs for diabetes therapy: why no clinically useful drug after two decades of trying? Trends Pharmacol Sci 34, 90-99.

8. Cárdenas ML (2004) Comparative biochemistry of glucokinase. In Glucokinase and Glycemic Disease: From Basics to Novel Therapeutics, vol. 16, pp. 31-41 [FM Matschinsky and MA Magnuson, editors]. Basel: Karger.

9. Matschinsky FM \& Ellerman JE (1968) Metabolism of glucose in the islets of Langerhans. J Biol Chem 243, 2730-2736.

10. Bedoya FJ, Wilson JM, Ghosh AK, et al. (1986) The glucokinase glucose sensor in human pancreatic islet tissue. Diabetes 35, 61-67.

11. Matschinsky FM (1990) Glucokinase as glucose sensor and metabolic signal generator in pancreatic $\beta$-cells and hepatocytes. Diabetes 39, 647-652.

12. Magnuson MA (1990) Perspectives in diabetes: glucokinase gene structure: functional implications of molecular genetic studies. Diabetes 39, 523-527.

13. Magnuson MA \& Shelton KD (1989) An alternate promoter in the glucokinase gene is active in the pancreatic $\beta$ cell. J Biol Chem 264, 15936-15942.

14. Jetton TL, Liang Y, Pettepher CC, et al. (1994) Analysis of upstream glucokinase promoter activity in transgenic mice and identification of glucokinase in rare neuroendocrine cells in the brain and gut. J Biol Chem 269, 3641-3654.

15. Heimberg H, De Vos A, Moens K, et al. (1996) The glucose sensor protein glucokinase is expressed in glucagonproducing $\alpha$-cells. Proc Natl Acad Sci U S A 93, 7036-7041.

16. Zelent D, Golson ML, Koeberlein B, et al. (2006) A glucose sensor role for glucokinase in anterior pituitary cells. Diabetes 55, 1923-1929.

17. Iynedjian PB, Pilot PR, Nouspikel T, et al. (1989) Differential expression and regulation of the glucokinase gene in liver and islets of Langerhans. Proc Natl Acad Sci U S A 86, $7838-7842$.

18. Matschinsky FM, Liang Y, Kesavan P, et al. (1993) Glucokinase as pancreatic $\beta$ cell glucose sensor and diabetes gene. J Clin Invest 92, 2092-2098.

19. Matschinsky FM (2002) Regulation of pancreatic $\beta$-cell glucokinase: from basics to therapeutics. Diabetes $\mathbf{5 1}$, Suppl. 3, S394-S404.

20. Cornish-Bowden A \& Cárdenas ML (2004) Glucokinase: a monomeric enzyme with positive cooperativity. In Glucokinase and Glycemic Disease: From Basics to Novel Therapeutics, vol. 16, pp. 125-134 [FM Matschinsky and MA Magnuson, editors]. Basel: Karger.

21. Baltrusch S, Wu C, Okar D, et al (2004) Interaction of GK with the bifunctional enzyme 6-phosphofructo2-kinase/fructose-2, 6-bisphosphatase (6PF2K/F26P2ase). In Glucokinase and Glycemic Disease: From Basics to 
Novel Therapeutics, vol. 16, pp. 262-274 [FM Matschinsky and MA Magnuson, editors]. Basel: Karger.

22. van Schaftingen E, Veiga-da-Cunha M \& Niculescu L (1997) The regulatory protein of glucokinase. Biochem Soc Trans 25, 136-140.

23. Vandercammen A \& van Schaftingen E (1990) The mechanism by which rat liver glucokinase is inhibited by the regulatory protein. Eur J Biochem 191, 483-489.

24. Toyoda Y, Miwa I, Kamiya M, et al. (1995) Changes in subcellular and zonal distribution of glucokinase in rat liver during postnatal development. FEBS Lett 359, 81-84.

25. Brown KS, Kalinowski SS, Megill JR, et al. (1997) Glucokinase regulatory protein may interact with glucokinase in the hepatocyte nucleus. Diabetes 46, 179-186.

26. Jiang MH, Fei J, Lan MS, et al. (2008) Hypermethylation of hepatic Gck promoter in ageing rats contributes to diabetogenic potential. Diabetologia 51, 1525-1533.

27. Kim JY, Song EH, Lee HJ, et al. (2010) Chronic ethanol consumption-induced pancreatic $\beta$-cell dysfunction and apoptosis through glucokinase nitration and its downregulation. J Biol Chem 285, 37251-37262.

28. Li X, Li H, Lu N, et al. (2012) Iron increases liver injury through oxidative/nitrative stress in diabetic rats: involvement of nitrotyrosination of glucokinase. Biochimie $\mathbf{9 4}$, $2620-2627$.

29. Fernandez-Mejia C \& German MS (2004) Regulation of glucokinase by vitamins and hormones. In Glucokinase and Glycemic Disease: From Basics to Novel Therapeutics, vol. 16, pp. 240-248 [FM Matschinsky and MA Magnuson, editors]. Basel: Karger.

30. McCarty MF (1999) High-dose biotin, an inducer of glucokinase expression, may synergize with chromium picolinate to enable a definitive nutritional therapy for type II diabetes. Med Hypotheses 52, 401-406.

31. Borboni P, Magnaterra R, Rabini RA, et al. (1996) Effect of biotin on glucokinase activity, mRNA expression and insulin release in cultured $\beta$-cells. Acta Diabetol 33, 154-158.

32. Petersen KF, Laurent D, Yu C, et al. (2001) Stimulating effects of low-dose fructose on insulin-stimulated hepatic glycogen synthesis in humans. Diabetes 50, 1263-1268.

33. Moore MC, Davis SN, Mann SL, et al. (2001) Acute fructose administration improves oral glucose tolerance in adults with type 2 diabetes. Diabetes Care 24, 1882-1887.

34. Dekker MJ, Su Q, Baker C, et al. (2010) Fructose: a highly lipogenic nutrient implicated in insulin resistance, hepatic steatosis, and the metabolic syndrome. Am J Physiol Endocrinol Metab 299, E685-E694

35. Tappy L \& Lê K-A (2010) Metabolic effects of fructose and the worldwide increase in obesity. Physiol Rev 90, 23-46.

36. DiPietro DL \& Weinhouse S (1960) Hepatic glucokinase in the fed, fasted, and alloxan-diabetic rat. J Biol Chem 235, $2542-2545$.

37. Viñuela E, Salas M \& Sols A (1963) Glucokinase and hexokinase in liver in relation to glycogen synthesis. $J$ Biol Chem 238, PC1175-PC1177.

38. Abraham S, Borrebaek B \& Chaikoff IL (1964) Effect of dietary carbohydrate and glucokinase and mannokinase activities of various rat tissues. $J$ Nutr $\mathbf{8 3}, 273-288$.

39. Salas M, Vinuela E \& Sols A (1963) Insulin-dependent synthesis of liver glucokinase in the rat. $J$ Biol Chem 238, 3535-3538.

40. Sharma C, Manjeshwar R \& Weinhouse S (1963) Effects of diet and insulin on glucose-adenosine triphosphate phosphotransferases of rat liver. J Biol Chem 238, 3840-3845.

41. Stanley JC, Dohm GL, McManus BS, et al. (1984) Activities of glucokinase and hexokinase in mammalian and avian livers. Biochem J 224, 667-671.
42. Brown J, Miller DM, Holloway MT, et al. (1967) Hexokinase isoenzymes in liver and adipose tissue of man and dog. Science 155, 205-207.

43. Sibrowski W \& Seitz HJ (1984) Rapid action of insulin and cyclic AMP in the regulation of functional messenger RNA coding for glucokinase in rat liver. $J$ Biol Chem 259, 343-346.

44. Iritani N, Fukuda H, Tada K, et al. (1995) Diet differentially regulates glucokinase and L-type pyruvate kinase gene expression in rat liver. J Nutr 125, 2945-2952.

45. Vandercammen A \& van Schaftingen E (1993) Species and tissue distribution of the regulatory protein of glucokinase. Biochem J 294, 551-556.

46. Fernández-Novell JM, Castel S, Bellido D, et al. (1999) Intracellular distribution of hepatic glucokinase and glucokinase regulatory protein during the fasted to refed transition in rats. FEBS Lett 459, 211-214.

47. Polakof S, Miguez JM \& Soengas JL (2009) A hepatic protein modulates glucokinase activity in fish and avian liver: a comparative study. J Comp Physiol B Biochem Syst Environ Physiol 179, 643-652.

48. Tiedge M \& Lenzen S (1991) Regulation of glucokinase and GLUT-2 glucose-transporter gene expression in pancreatic $\beta$-cells. Biochem J 279, 899-901.

49. Chen C, Bumbalo L \& Leahy JL (1994) Increased catalytic activity of glucokinase in isolated islets from hyperinsulinemic rats. Diabetes 43, 684-689.

50. Liang Y, Najafi H, Smith RM, et al. (1992) Concordant glucose induction of glucokinase, glucose usage, and glucose-stimulated insulin release in pancreatic islets maintained in organ culture. Diabetes 41, 792-806.

51. Lenzen S, Tiedge M, Flatt PR, et al. (1987) Defective regulation of glucokinase in rat pancreatic islet cell tumours Acta Endocrinol (Copenh) 115, 514-520.

52. Burch PT, Trus MD, Berner DK, et al. (1981) Adaptation of glycolytic enzymes: glucose use and insulin release in rat pancreatic islets during fasting and refeeding. Diabetes $\mathbf{3 0}$, 923-928.

53. Meglasson MD \& Matschinsky FM (1984) New perspectives on pancreatic islet glucokinase. Am J Physiol Endocrinol Metab 246, E1-E13

54. Chen C, Hosokawa H, Bumbalo LM, et al. (1994) Regulatory effects of glucose on the catalytic activity and cellular content of glucokinase in the pancreatic $\beta$ cell. Study using cultured rat islets. J Clin Invest 94, 1616-1620.

55. Jörns A, Tiedge M \& Lenzen S (1999) Nutrient-dependent distribution of insulin and glucokinase immunoreactivities in rat pancreatic $\beta$ cells. Virchows Arch 434, 75-82.

56. Hussain K (2010) Mutations in pancreatic $\beta$-cell glucokinase as a cause of hyperinsulinaemic hypoglycaemia and neonatal diabetes mellitus. Rev Endocr Metab Disord 11, 179-183.

57. Bell GI, Pilkis SJ, Weber IT, et al. (1996) Glucokinase mutations, insulin secretion, and diabetes mellitus. Annu Rev Physiol 58, 171-186.

58. Polonsky KS (1995) Lilly Lecture 1994. The $\beta$-cell in diabetes: from molecular genetics to clinical research. Diabetes 44, 705-717.

59. Klupa T, Solecka I, Nowak N, et al. (2011) The influence of dietary carbohydrate content on glycaemia in patients with glucokinase maturity-onset diabetes of the young. J Int Med Res 39, 2296-2301.

60. Blumenthal MD, Abraham S \& Chaikoff IL (1964) Dietary control of liver glucokinase activity in the normal rat. Arch Biochem Biophys 104, 215-224.

61. Iynedjian PB, Ucla C \& Mach B (1987) Molecular cloning of glucokinase cDNA. Developmental and dietary regulation 
of glucokinase mRNA in rat liver. $J$ Biol Chem 262 6032-6038.

62. Pérez N, Clark-Turri L, Rabajille E, et al. (1964) Regulation of rat liver enzymes by natural components of the diet. J Biol Chem 239, 2420-2426.

63. Borrebaek B, Hultman E, Nilsson LHS, et al. (1970) Adaptable glucokinase activity of human liver. Biochem Med $\mathbf{4}$, 469-475.

64. Chu CA, Fujimoto Y, Igawa K, et al. (2004) Rapid translocation of hepatic glucokinase in response to intraduodenal glucose infusion and changes in plasma glucose and insulin in conscious rats. Am J Physiol Gastrointest Liver Physiol 286, G627-G634.

65. Fujimoto Y, Donahue EP \& Shiota M (2004) Defect in glucokinase translocation in Zucker diabetic fatty rats. Am J Physiol Endocrinol Metab 287, E414-E423.

66. Agius L (2008) Glucokinase and molecular aspects of liver glycogen metabolism. Biochem J 414, 1-18.

67. Toyoda Y, Tsuchida A, Iwami E, et al. (2001) Regulation of hepatic glucose metabolism by translocation of glucokinase between the nucleus and the cytoplasm in hepatocytes. Horm Metab Res 33, 329-336.

68. Watford M (2002) Small amounts of dietary fructose dramatically increase hepatic glucose uptake through a novel mechanism of glucokinase activation. Nutr Rev $\mathbf{6 0}$, 253-257.

69. McGuinness OP \& Cherrington AD (2003) Effects of fructose on hepatic glucose metabolism. Curr Opin Clin Nutr Metab Care 6, 441-448.

70. Ly J \& Torres MA (2011) Fructose metabolism in pigs fed sugar cane molasses. Rev Comp Prod Porcina 18, 252-254.

71. Walker DG (1962) The development of hepatic hexokinases after birth. Biochem J 84, 118P.

72. Walker DG \& Holland G (1965) The development of hepatic glucokinase in the neonatal rat. Biochem J 97, 845-854.

73. Haney PM, Estrin CR, Caliendo A, et al. (1986) Precocious induction of hepatic glucokinase and malic enzyme in artificially reared rat pups fed a high-carbohydrate diet. Arch Biochem Biophys 244, 787-794.

74. Walker DG \& Eaton SW (1967) Regulation of development of hepatic glucokinase in the neonatal rat by the diet. Biochem J 105, 771-777.

75. Liang Y, Najafi H \& Matschinsky FM (1990) Glucose regulates glucokinase activity in cultured islets from rat pancreas. J Biol Chem 265, 16863-16866.

76. Tiedge $M$ \& Lenzen S (1995) Effects of glucose refeeding and glibenclamide treatment on glucokinase and GLUT2 gene expression in pancreatic $\beta$-cells and liver from rats. Biochem J 308, 139-144.

77. Langer S, Kaminski MT, Lenzen S, et al. (2010) Endogenous activation of glucokinase by 6-phosphofructo-2-kinase/ fructose-2,6-bisphosphatase is glucose dependent. Mol Endocrinol 24, 1988-1997.

78. Maiztegui B, Borelli MI, Raschia MA, et al. (2009) Islet adaptive changes to fructose-induced insulin resistance: $\beta$-cell mass, glucokinase, glucose metabolism, and insulin secretion. J Endocrinol 200, 139-149.

79. Ferreira Mdel R, Lombardo YB \& Chicco A (2010) $\beta$-Cell adaptation/dysfunction in an animal model of dyslipidemia and insulin resistance induced by the chronic administration of a sucrose-rich diet. Islets 2, 367-373.

80. Álvarez E, Roncero I, Chowen JA, et al. (2002) Evidence that glucokinase regulatory protein is expressed and interacts with glucokinase in rat brain. J Neurochem 80, 45-53.

81. Mohanasundaram D, Drogemuller C, Brealey J, et al. (2011) Ultrastructural analysis, zinc transporters, glucose transporters and hormones expression in New World primate
(Callithrix jacchus) and human pancreatic islets. Gen Comp Endocrinol 174, 71-79.

82. Vaughan DA, Hannon JP \& Vaughan LN (1960) Effects of diet on selected glycolytic enzymes of the rat. Am J Physiol Endocrinol Metab 199, 1041-1044.

83. Niemeyer H, Clark-Turri L, Garcés E, et al. (1962) Selective response of liver enzymes to the administration of different diets after fasting. Arch Biochem Biophys 98, 77-85.

84. Stepien M, Gaudichon C, Fromentin G, et al. (2011) Increasing protein at the expense of carbohydrate in the diet down-regulates glucose utilization as glucose sparing effect in rats. PLOS ONE 6, e14664.

85. Higuchi N, Kato M, Miyazaki M, et al. (2011) Potential role of branched-chain amino acids in glucose metabolism through the accelerated induction of the glucose-sensing apparatus in the liver. $J$ Cell Biochem 112, 30-38.

86. Keller J, Ringseis R, Priebe S, et al. (2011) Effect of L-carnitine on the hepatic transcript profile in piglets as animal model. Nutr Metab (Lond) 8, 76 .

87. Heywood WE, Mian N, Milla PJ, et al. (2004) Programming of defective rat pancreatic $\beta$-cell function in offspring from mothers fed a low-protein diet during gestation and the suckling periods. Clin Sci 107, 37-45.

88. Batista TM, da Silva PM, Amaral AG, et al. (2013) Taurine supplementation restores insulin secretion and reduces ER stress markers in protein-malnourished mice. Adv Exp Med Biol 776, 129-139.

89. Carneiro EM, Latorraca MQ, Araujo E, et al. (2009) Taurine supplementation modulates glucose homeostasis and islet function. J Nutr Biochem 20, 503-511.

90. de Oliveira CA, Latorraca MQ, de Mello MA, et al. (2011) Mechanisms of insulin secretion in malnutrition: modulation by amino acids in rodent models. Amino Acids $\mathbf{4 0}$, 1027-1034.

91. Tsukita S, Yamada T, Uno K, et al. (2012) Hepatic glucokinase modulates obesity predisposition by regulating BAT thermogenesis via neural signals. Cell Metab 16, 825-832.

92. Oakes ND, Cooney GJ, Camilleri S, et al. (1997) Mechanisms of liver and muscle insulin resistance induced by chronic high-fat feeding. Diabetes 46, 1768-1774.

93. Peng Y, Rideout D, Rakita S, et al. (2012) Diet-induced obesity associated with steatosis, oxidative stress, and inflammation in liver. Surg Obes Relat Dis 8, 73-81.

94. Zulet MA, Barber A, Garcin H, et al. (1999) Alterations in carbohydrate and lipid metabolism induced by a diet rich in coconut oil and cholesterol in a rat model. $\mathrm{J} \mathrm{Am} \mathrm{Coll}$ Nutr 18, 36-42.

95. Tippett PS \& Neet KE (1982) Specific inhibition of glucokinase by long chain acyl coenzymes A below the critical micelle concentration. J Biol Chem 257, 12839-12845.

96. Agius L \& Peak M (1997) Binding and translocation of glucokinase in hepatocytes. Biochem Soc Trans 25, 145-150.

97. Jump DB, Clarke SD, Thelen A, et al. (1994) Coordinate regulation of glycolytic and lipogenic gene expression by polyunsaturated fatty acids. J Lipid Res 35, 1076-1084.

98. Lam TK, Carpentier A, Lewis GF, et al. (2003) Mechanisms of the free fatty acid-induced increase in hepatic glucose production. Am J Physiol Endocrinol Metab 284, E863-E873.

99. Perez-Martinez P, Garcia-Rios A, Delgado-Lista J, et al. (2012) Metabolic syndrome: evidences for a personalized nutrition. Mol Nutr Food Res 56, 67-76.

100. Kim YB, Iwashita S, Tamura T, et al. (1995) Effect of highfat diet on the gene expression of pancreatic GLUT2 and glucokinase in rats. Biochem Biophys Res Commun 208, 1092-1098. 
101. Gremlich S, Bonny C, Waeber G, et al. (1997) Fatty acids decrease IDX-1 expression in rat pancreatic islets and reduce GLUT2, glucokinase, insulin, and somatostatin levels. J Biol Chem 272, 30261-30269.

102. Cerf ME, Muller CJ, Du Toit DF, et al. (2006) Hyperglycaemia and reduced glucokinase expression in weanling offspring from dams maintained on a high-fat diet. $\mathrm{BrJ}$ Nutr 95, 391-396.

103. Cerf ME, Williams K, Chapman CS, et al. (2007) Compromised $\beta$-cell development and $\beta$-cell dysfunction in weanling offspring from dams maintained on a high-fat diet during gestation. Pancreas 34, 347-353.

104. Cerf ME, Chapman CS, Muller CJ, et al. (2009) Gestational high-fat programming impairs insulin release and reduces Pdx-1 and glucokinase immunoreactivity in neonatal Wistar rats. Metabolism 58, 1787-1792.

105. Walker DG \& Rao S (1964) The role of glucokinase in the phosphorylation of glucose by rat liver. Biochem $J \mathbf{9 0}$, 360-368.

106. Iynedjian PB, Jotterand D, Nouspikel T, et al. (1989) Transcriptional induction of glucokinase gene by insulin in cultured liver cells and its repression by the glucagoncAMP system. J Biol Chem 264, 21824-21829.

107. Shin J-S, Torres TP, Catlin RL, et al. (2007) A defect in glucose-induced dissociation of glucokinase from the regulatory protein in Zucker diabetic fatty rats in the early stage of diabetes. Am J Physiol Regul Integr Comp Physiol 292, R1381-R1390.

108. Willms B, Ben-Ami P \& Söling HD (1970) Hepatic enzyme activities of glycolysis and gluconeogenesis in diabetes of man and laboratory animals. Horm Metab Res 2, $135-141$.

109. Iynedjian PB, Marie S, Gjinovci A, et al. (1995) Glucokinase and cytosolic phosphoenolpyruvate carboxykinase (GTP) in the human liver. Regulation of gene expression in cultured hepatocytes. J Clin Invest 95, 1966-1973.

110. Peter A, Stefan N, Cegan A, et al. (2011) Hepatic glucokinase expression is associated with lipogenesis and fatty liver in humans. J Clin Endocrinol Metab 96, E1126-E1130.

111. Jörns A, Tiedge M, Ziv E, et al. (2002) Gradual loss of pancreatic $\beta$-cell insulin, glucokinase and GLUT2 glucose transporter immunoreactivities during the time course of nutritionally induced type-2 diabetes in Psammomys obesus (sand rat). Virchows Arch 440, 63-69.

112. Terauchi Y, Takamoto I, Kubota N, et al. (2007) Glucokinase and IRS-2 are required for compensatory $\beta$ cell hyperplasia in response to high-fat diet-induced insulin resistance. J Clin Invest 117, 246-257.

113. Goran MI, Walker R \& Allayee H (2012) Genetic-related and carbohydrate-related factors affecting liver fat accumulation. Curr Opin Clin Nutr Metab Care 15, 392-396.

114. Nettleton JA, McKeown NM, Kanoni S, et al. (2010) Interactions of dietary whole-grain intake with fasting glucose- and insulin-related genetic loci in individuals of European descent: a meta-analysis of 14 cohort studies. Diabetes Care 33, 2684-2691.

115. Del Guerra S, Lupi R, Marselli L, et al. (2005) Functional and molecular defects of pancreatic islets in human type 2 diabetes. Diabetes 54, 727-735.

116. Yang J, Wong RK, Park M, et al. (2006) Leucine regulation of glucokinase and ATP synthase sensitizes glucose-induced insulin secretion in pancreatic $\beta$-cells. Diabetes $\mathbf{5 5}$, 193-201.

117. Le Marchand SJ \& Piston DW (2010) Glucose suppression of glucagon secretion: metabolic and calcium responses from $\alpha$-cells in intact mouse pancreatic islets. J Biol Chem 285 , 14389-14398.
118. Dierenfeld ES, Alcorn HL \& Jacobsen KL (2002) Nutrient Composition of Whole Vertebrate Prey (Excluding Fish) Fed in Zoos. http://www.nal.usda.gov/awic/zoo/Whole PreyFinal02May29.pdf (accessed March 2014)

119. Verbrugghe A, Hesta M, Daminet S, et al. (2012) Nutritional modulation of insulin resistance in the true carnivorous cat: a review. Crit Rev Food Sci Nutr 52, 172-182.

120. Thiess S, Becskei C, Tomsa K, et al. (2004) Effects of high carbohydrate and high fat diet on plasma metabolite levels and on i.v. glucose tolerance test in intact and neutered male cats. J Feline Med Surg 6, 207-218.

121. MacDonald ML, Rogers QR \& Morris JG (1984) Nutrition of the domestic cat, a mammalian carnivore. Annu Rev Nutr $\mathbf{4}$, $521-562$.

122. Zoran DL (2002) The carnivore connection to nutrition in cats. J Am Vet Med Assoc 221, 1559-1567.

123. Brand Miller JC \& Colagiuri S (1994) The carnivore connection: dietary carbohydrate in the evolution of NIDDM. Diabetologia 37, 1280-1286.

124. Colagiuri S \& Brand Miller J (2002) The "carnivore connection'-evolutionary aspects of insulin resistance. Eur J Clin Nutr 56, Suppl. 1, S30-S35.

125. Washizu T, Tanaka A, Sako T, et al. (1999) Comparison of the activities of enzymes related to glycolysis and gluconeogenesis in the liver of dogs and cats. Res Vet Sci $\mathbf{6 7}$, 205-206.

126. Tanaka A, Inoue A, Takeguchi A, et al. (2005) Comparison of expression of glucokinase gene and activities of enzymes related to glucose metabolism in livers between dog and cat. Vet Res Commun 29, 477-485.

127. Jackson TC, Debey B, Lindbloom-Hawley S, et al. (2009) Cellular and molecular characterization of a feline insulinoma. J Vet Intern Med 23, 383-387.

128. Hiskett EK, Suwitheechon OU, Lindbloom-Hawley S, et al. (2008) Lack of glucokinase regulatory protein expression may contribute to low glucokinase activity in feline liver. Vet Res Commun 33, 227-240.

129. Moore MC, Coate KC, Winnick JJ, et al. (2012) Regulation of hepatic glucose uptake and storage in vivo. Adv Nutr 3, 286-294.

130. Hewson-Hughes AK, Gilham MS, Upton S, et al. (2011) Postprandial glucose and insulin profiles following a glucose-loaded meal in cats and dogs. Br J Nutr 106, S101-S104.

131. Kirk CA, Debraekeleer J \& Armstrong PJ (2000) Normal cats. In Small Animal Clinical Nutrition, pp. 291-351 [MS Hand, CD Thatcher and ML Remillard, editors]. Philadelphia, PA: WB Saunders Co..

132. Hornichter R, Brown J \& Snow H (1967) Effects of starvation and diabetes on glucokinase activity in dog liver. Clin Res 15, 109 .

133. Liu MS \& Sharma C (1981) Glycolytic enzyme activities in normal and diabetic dog livers during endotoxic shock. Am J Physiol Regul Integr Comp Physiol 240, R10-R15.

134. Shiota M, Galassetti P, Monohan M, et al. (1998) Small amounts of fructose markedly augment net hepatic glucose uptake in the conscious dog. Diabetes 47, 867-873.

135. Chen SS, Santomango TS, Williams PE, et al. (2009) Glucagon-mediated impairments in hepatic and peripheral tissue nutrient disposal are not aggravated by increased lipid availability. Am J Physiol Endocrinol Metab 296, E1172-E1178.

136. Coate KC, Kraft G, Irimia JM, et al. (2013) Portal vein glucose entry triggers a coordinated cellular response that potentiates hepatic glucose uptake and storage in normal but not high-fat/high-fructose-fed dogs. Diabetes 62, $392-400$. 
137. Coate KC, Smith MS, Shiota M, et al. (2013) Hepatic glucose metabolism in late pregnancy: normal versus high-fat and -fructose diet. Diabetes 62, 753-761.

138. Arai T, Washizu T, Sagara M, et al. (1995) D-Glucose transport and glycolytic enzyme activities in erythrocytes of dogs, pigs, cats, horses, cattle and sheep. Res Vet Sci 58, 195-196.

139. Kaneko JJ, Harvey JW \& Bruss ML (2008) Apendix VII Blood analyte reference value for large animals. In Clinical Biochemistry of Domestic Animals [JJ Kaneko, JW Harvey and ML Bruss, editors]. London: Academic Press.

140. Farningham DA \& Whyte CC (1993) The role of propionate and acetate in the control of food intake in sheep. BrJ Nutr 70, 37-46.

141. Allen MS, Bradford BJ \& Oba M (2009) Board Invited Review: The hepatic oxidation theory of the control of feed intake and its application to ruminants. J Anim Sci 87, 3317-3334.

142. Tanaka A, Urabe S, Takeguchi A, et al. (2006) Comparison of activities of enzymes related to energy metabolism in peripheral leukocytes and livers between Holstein dairy cows and ICR mice. Vet Res Commun 30, 29-38.

143. Hyatt MA, Gardner DS, Sebert S, et al. (2011) Suboptimal maternal nutrition, during early fetal liver development, promotes lipid accumulation in the liver of obese offspring. Reproduction 141, 119-126.

144. Scanes CG \& Braun E (2013) Avian metabolism: its control and evolution. Front Biol 8, 134-159.

145. Polakof S, Mommsen TP \& Soengas JL (2011) Glucosensing and glucose homeostasis: from fish to mammals. Comp Biochem Physiol A Mol Integr Physiol 160, 123-149.

146. Pollock C (2002) Carbohydrate regulation in avian species. Semin Avian Exotic Pet Med 11, 57-64.

147. Braun EJ \& Sweazea KL (2008) Glucose regulation in birds. Comp Biochem Physiol B Biochem Mol Biol 151, 1-9.

148. Scanes CG (2009) Perspectives on the endocrinology of poultry growth and metabolism. Gen Comp Endocrinol 163, 24-32.

149. Seki Y, Sato K, Kono T, et al. (2003) Broiler chickens (Ross strain) lack insulin-responsive glucose transporter GLUT4 and have GLUT8 cDNA. Gen Comp Endocrinol 133, 80-87.

150. Berradi H, Guy G \& Rideau N (2004) A glucokinase-like enzyme induced in mule duck livers by overfeeding. Poult Sci 83, 161-168.

151. Ureta $\mathrm{T}$ (1982) The comparative isozymology of vertebrate hexokinases. Comp Biochem Physiol B 71, 549-555.

152. Ureta T, Medina C \& Preller A (1987) The evolution of hexokinases. Arch Biol Med Exp (Santiago) 20, 343-357.

153. Tranulis MA, Dregni O, Christophersen B, et al. (1996) A glucokinase-like-enzyme in the liver of Atlantic salmon (Salmo salar). Comp Biochem Physiol A Physiol 114, 35-39.

154. Wals PA \& Katz J (1981) Glucokinase in bird liver: a membrane bound enzyme. Biochem Biophys Res Commun 100, 1543-1548.

155. Ureta T, Reichberg SB, Radojkovic J, et al. (1973) Comparative studies on glucose phosphorylating isoenzymes of vertebrates. IV. Chromatographic profiles of hexokinases from the liver of several avian species. Comp Biochem Physiol B 45, 445-461.

156. Davagnino J \& Ureta T (1980) The identification of extrahepatic "glucokinase" as $N$-acetylglucosamine kinase. J Biol Chem 255, 2633-2636.

157. Klandorf H, Clarke BL, Scheck AC, et al. (1986) Regulation of glucokinase activity in the domestic fowl. Biochem Biophys Res Commun 139, 1086-1093.

158. Panserat S, Blin C \& Médale F (2000) Molecular cloning, tissue distribution and sequence analysis of complete glucokinase cDNAs from gilthead seabream (Sparus aurata), rainbow trout (Oncorbynchus mykiss) and common carp (Cyprinus carpio). Biochim Biophys Acta 1474, 61-69.

159. Berradi H, Taouis M, Cassy S, et al. (2005) Glucokinase in chicken (Gallus gallus). Partial cDNA cloning, immunodetection and activity determination. Comp Biochem Physiol B Biochem Mol Biol 141, 129-139.

160. Berradi H, Bernadet MD, Guy G, et al. (2007) Expression of the glucokinase gene in mule duck liver and glucokinase activities in chicken and mule duck livers. Poult Sci 86, 2216-2220.

161. Rideau N, Derouet M, Grimsby J, et al. (2010) Glucokinase activation induces potent hypoglycemia without recruiting insulin and inhibits food intake in chicken. Gen Comp Endocrinol 169, 276-283.

162. Myers MR \& Klasing KC (1999) Low glucokinase activity and high rates of gluconeogenesis contribute to hyperglycemia in barn owls (Tyto alba) after a glucose challenge. J Nutr 129, 1896-1904.

163. Rideau N, Berradi H, Skiba-Cassy S, et al. (2008) Induction of glucokinase in chicken liver by dietary carbohydrates. Gen Comp Endocrinol 158, 173-177.

164. Panserat S, Médale F, Blin C, et al. (2000) Hepatic glucokinase is induced by dietary carbohydrates in rainbow trout, gilhead seabream, and common carp. Am J Physiol Regul Integr Comp Physiol 278, R1164-R1170.

165. Bedu E, Chainier F, Sibille B, et al. (2002) Increased lipogenesis in isolated hepatocytes from cold-acclimated ducklings. Am J Physiol Regul Integr Comp Physiol 283, R1245-R1253.

166. Mourot J, Guy G, Lagarrigue S, et al. (2000) Role of hepatic lipogenesis in the susceptibility to fatty liver in the goose (Anser anser). Comp Biochem Physiol B Biochem Mol Biol 126, 81-87.

167. Hsu JC, Tanaka K, Inayama I, et al. (1992) Effects of pantethine on lipogenesis and $\mathrm{CO}_{2}$ production in the isolated hepatocytes of the chick (Gallus domesticus). Comp Biochem Physiol Comp Physiol 102, 569-572.

168. Nadaf J, Pitel F, Gilbert H, et al. (2009) QTL for several metabolic traits map to loci controlling growth and body composition in an $\mathrm{F}_{2}$ intercross between high- and lowgrowth chicken lines. Physiol Genomics 38, 241-249.

169. Dupont J, Tesseraud S, Derouet M, et al. (2008) Insulin immuno-neutralization in chicken: effects on insulin signaling and gene expression in liver and muscle. J Endocrinol 197, $531-542$

170. Harrison RW \& Weber IT (2004) Molecular models of human glucokinase and the implications for glycemic diseases. In Glucokinase and Glycemic Disease: From Basics to Novel Therapeutics, vol. 16, pp. 135-144 [FM Matschinsky and MA Magnuson, editors]. Basel: Karger.

171. Dunten P, Swain A, Kammlott U, et al (2004) Crystal structure of human liver glucokinase bound to a small molecule allosteric activator. In Glucokinase and Glycemic Disease: From Basics to Novel Therapeutics, vol. 16, pp. 145-154 [FM Matschinsky and MA Magnuson, editors]. Basel: Karger.

172. Baltrusch S \& Tiedge M (2006) Glucokinase regulatory network in pancreatic $\beta$-cells and liver. Diabetes 55, S55-S64.

173. Baltrusch S, Francini F, Lenzen S, et al. (2005) Interaction of glucokinase with the liver regulatory protein is conferred by leucine-asparagine motifs of the enzyme. Diabetes $\mathbf{5 4}$, 2829-2837.

174. Velho G, Froguel P, Gloyn A, et al (2004) Maturity onset diabetes of the young type 2. In Glucokinase and Glycemic Disease: From Basics to Novel Therapeutics, vol. 16, pp. 42-64 [FM Matschinsky and MA Magnuson, editors]. Basel: Karger. 
175. Grimsby J, Matschinsky FM \& Grippo JF (2004) Discovery and actions of glucokinase activators. In Glucokinase and Glycemic Disease: From Basics to Novel Therapeutics, vol. 16, pp. 360-378 [FM Matschinsky and MA Magnuson, editors]. Basel: Karger.

176. Liang Y, Jetton TL, Zimmerman EC, et al. (1991) Effects of alternate RNA splicing on glucokinase isoform activities in the pancreatic islet, liver, and pituitary. J Biol Chem 266, 6999-7007.

177. Magnuson MA (1990) Glucokinase gene structure. Functional implications of molecular genetic studies. Diabetes 39, 523-527.

178. Toyoda Y, Miwa I, Kamiya M, et al. (1995) Tissue and subcellular distribution of glucokinase in rat liver and their changes during fasting-refeeding. Histochem Cell Biol 103, 31-38.

179. Dhahbi JM, Mote PL, Wingo J, et al. (2001) Caloric restriction alters the feeding response of key metabolic enzyme genes. Mech Ageing Dev 122, 1033-1048.

180. Minderop RH, Hoeppner W \& Seitz HJ (1987) Regulation of hepatic glucokinase gene expression. Role of carbohydrates, and glucocorticoid and thyroid hormones. Eur J Biochem 164, 181-187.

181. Sibrowski W \& Seitz HJ (1980) Hepatic glucokinase turnover in intact and adrenalectomized rats in vivo. Eur J Biochem 113, 121-129.

182. Chartrin P, Bernadet MD, Guy G, et al. (2006) Does overfeeding enhance genotype effects on liver ability for lipogenesis and lipid secretion in ducks? Comp Biochem Physiol A Mol Integr Physiol 145, 390-396.

183. Narkewicz MR, Iynedjian PB, Ferre P, et al. (1990) Insulin and tri-iodothyronine induce glucokinase mRNA in primary cultures of neonatal rat hepatocytes. Biochem $J \mathbf{2 7 1}$, 585-589.

184. Postic C \& Magnuson MA (1999) Role of glucokinase (GK) in the maintenance of glucose homeostasis. Specific disruption of the gene by the Cre-loxP technique (article in French). Journ Annu Diabetol Hotel Dieu 1999, 115-124.

185. Grimsby J, Sarabu R, Corbett WL, et al. (2003) Allosteric activators of glucokinase: potential role in diabetes therapy. Science 301, 370-373.

186. Leighton B, Atkinson A \& Coghlan MP (2005) Small molecule glucokinase activators as novel anti-diabetic agents. Biochem Soc Trans 33, 371-374.

187. Futamura M, Hosaka H, Kadotani A, et al. (2006) An allosteric activator of glucokinase impairs the interaction of glucokinase and glucokinase regulatory protein and regulates glucose metabolism. J Biol Chem 281, 37668-37674.

188. Rideau N (1998) Peculiarities of insulin secretion in chickens. Ann N Y Acad Sci 839, 162-165.

189. Dupont J, Dagou C, Derouet M, et al. (2004) Early steps of insulin receptor signaling in chicken and rat: apparent refractoriness in chicken muscle. Domest Anim Endocrinol 26, $127-142$.

190. Shurlock TG \& Forbes JM (1981) Evidence for hepatic glucostatic regulation of food intake in the domestic chicken and its interaction with gastro-intestinal control. $\mathrm{Br}$ Poult Sci 22, 333-346.

191. Moon TW (2001) Glucose intolerance in teleost fish: fact or fiction? Comp Biochem Physiol B Biochem Mol Biol 129, 243-249.

192. Hemre GI, Mommsen TP \& Krogdahl A (2002) Carbohydrates in fish nutrition: effects on growth, glucose metabolism and hepatic enzymes. Aquac Nutr 8, 175-194.

193. Polakof S, Panserat S, Soengas J, et al. (2012) Glucose metabolism in fish: a review. J Comp Physiol B 182, $1015-1045$.
194. Cowey CB, Walton MJ \& Halver J (1989) Intermediary metabolism. In Fish Nutrition, pp. 259-329 [J Halver, editor]. New York: Academic Press.

195. Hemre GI, Torrissen O, Krogdahl ^, et al. (1995) Glucose tolerance in Atlantic salmon, Salmo salar L., dependence on adaption to dietary starch and water temperature. Aquac Nutr 1, 69-75.

196. Wilson RP (1994) Utilization of dietary carbohydrate by fish. Aquaculture 124, 67-80.

197. Borrebaek B, Waagbø R, Christophersen B, et al. (1993) Adaptable hexokinase with low affinity for glucose in the liver of Atlantic salmon (Salmo salar). Comp Biochem Physiol B Biochem Mol Biol 106, 833-836.

198. Caseras A, Metón I, Fernández F, et al. (2000) Glucokinase gene expression is nutritionally regulated in liver of gilthead sea bream (Sparus aurata). Biochim Biophys Acta 1493, $135-141$.

199. Borrebaek B \& Christophersen B (2000) Hepatic glucose phosphorylating activities in perch (Perca fluviatilis) after differential dietary treatments. Comp Biochem Physiol B Biochem Mol Biol 125, 387-393.

200. Enes P, Panserat S, Kaushik S, et al. (2006) Effect of normal and waxy maize starch on growth, food utilization and hepatic glucose metabolism in European sea bass (Dicentrarchus labrax) juveniles. Comp Biochem Physiol B Biochem Mol Biol 143, 89-96.

201. González-Álvarez R, Ortega-Cuellar D, HernándezMendoza A, et al. (2009) The hexokinase gene family in the zebrafish: structure, expression, functional and phylogenetic analysis. Comp Biochem Physiol B Biochem Mol Biol 152, 189-195.

202. Enes P, Panserat S, Kaushik S, et al. (2009) Nutritional regulation of hepatic glucose metabolism in fish. Fish Physiol Biochem 35, 519-539.

203. Enes P, Panserat S, Kaushik S, et al. (2008) Hepatic glucokinase and glucose-6-phosphatase responses to dietary glucose and starch in gilthead sea bream (Sparus aurata) juveniles reared at two temperatures. Comp Biochem Physiol A Mol Integr Physiol 149, 80-86.

204. Skiba-Cassy S, Panserat S, Larquier M, et al. (2013) Apparent low ability of liver and muscle to adapt to variation of dietary carbohydrate:protein ratio in rainbow trout (Oncorhynchus mykiss). Br J Nutr 109, 1359-1372.

205. Pérez-Jiménez A, Guedes MJ, Morales AE, et al. (2007) Metabolic responses to short starvation and refeeding in Dicentrarchus labrax. Effect of dietary composition. Aquaculture 265, 325-335.

206. Polakof S, Moon TW, Aguirre P, et al. (2011) Glucose homeostasis in rainbow trout fed a high-carbohydrate diet: metformin and insulin interact in a tissue-dependent manner. Am J Physiol Regul Integr Comp Physiol 300, R166-R174.

207. Soengas JL, Polakof S, Chen X, et al. (2006) Glucokinase and hexokinase expression and activities in rainbow trout tissues: changes with food deprivation and refeeding. $A m$ J Physiol Regul Integr Comp Physiol 291, R810-R821.

208. Polakof S, Míguez JM, Moon TW, et al. (2007) Evidence for the presence of a glucosensor in hypothalamus, hindbrain, and Brockmann bodies of rainbow trout. Am J Physiol Regul Integr Comp Physiol 292, R1657-R1666.

209. Panserat S, Capilla E, Gutiérrez J, et al. (2001) Glucokinase is highly induced and glucose-6-phosphatase poorly repressed in liver of rainbow trout (Oncorbynchus mykiss) by a single meal with glucose. Comp Biochem Physiol B Biochem Mol Biol 128, 275-283.

210. Seiliez I, Panserat S, Lansard M, et al. (2011) Dietary carbohydrate to protein ratio affects TOR signaling and 
metabolism-related gene expression in the liver and muscle of rainbow trout after a single meal. Am J Physiol Regul Integr Comp Physiol 300, R733-R743.

211. Capilla E, Médale F, Panserat S, et al. (2004) Response of hexokinase enzymes and the insulin system to dietary carbohydrates in the common carp, Cyprinus carpio. Reprod Nutr Dev 44, 233-242.

212. Kumar S, Sahu NP, Pal AK, et al. (2009) Modulation of key metabolic enzyme of Labeo rohita (Hamilton) juvenile: effect of dietary starch type, protein level and exogenous $\alpha$-amylase in the diet. Fish Physiol Biochem 35, 301-315.

213. Leung LY \& Woo NY (2012) Influence of dietary carbohydrate level on endocrine status and hepatic carbohydrate metabolism in the marine fish Sparus sarba. Fish Physiol Biochem 38, 543-554.

214. Robison BD, Drew RE, Murdoch GK, et al. (2008) Sexual dimorphism in hepatic gene expression and the response to dietary carbohydrate manipulation in the zebrafish (Danio rerio). Comp Biochem Physiol D Genom Proteom 3, $141-154$

215. Shiau SY (1997) Utilization of carbohydrates in warmwater fish with particular reference to tilapia, Oreochromis niloticus X O. aureus. Aquaculture 151, 79-96.

216. Gao W, Liu YJ, Tian LX, et al. (2010) Effect of dietary carbohydrate-to-lipid ratios on growth performance, body composition, nutrient utilization and hepatic enzymes activities of herbivorous grass carp (Ctenopharyngodon idella). Aquacult Nutr 16, 327-333.

217. Enes P, Sanchez-Gurmaches J, Navarro I, et al. (2010) Role of insulin and IGF-I on the regulation of glucose metabolism in European sea bass (Dicentrarchus labrax) fed with different dietary carbohydrate levels. Comp Biochem Physiol A Mol Integr Physiol 157, 346-353.

218. Enes P, Panserat S, Kaushik S, et al. (2008) Growth performance and metabolic utilization of diets with native and waxy maize starch by gilthead sea bream (Sparus aurata) juveniles. Aquaculture 274, 101-108.

219. Metón I, Caseras A, Fernández F, et al. (2004) Molecular cloning of hepatic glucose-6-phosphatase catalytic subunit from gilthead sea bream (Sparus aurata): response of its mRNA levels and glucokinase expression to refeeding and diet composition. Comp Biochem Physiol B Biochem Mol Biol 138, 145-153.

220. Metón I, Fernández F \& Baanante IV (2003) Short- and long-term effects of refeeding on key enzyme activities in glycolysis-gluconeogenesis in the liver of gilthead seabream (Sparus aurata). Aquaculture 225, 99-107.

221. Couto A, Enes P, Peres H, et al. (2008) Effect of water temperature and dietary starch on growth and metabolic utilization of diets in gilthead sea bream (Sparus aurata) juveniles. Comp Biochem Physiol A Mol Integr Physiol 151, 45-50.

222. Moreira IS, Peres H, Couto A, et al. (2008) Temperature and dietary carbohydrate level effects on performance and metabolic utilisation of diets in European sea bass (Dicentrarchus labrax) juveniles. Aquaculture $\mathbf{2 7 4}$, 153-160.

223. Enes P, Panserat S, Kaushik S, et al. (2008) Rearing temperature enhances hepatic glucokinase but not glucose-6phosphatase activities in European sea bass (Dicentrarchus labrax) and gilthead sea bream (Sparus aurata) juveniles fed with the same level of glucose. Comp Biochem Physiol A Mol Integr Physiol 150, 355-358.

224. Panserat S, Perrin A \& Kaushik S (2002) High dietary lipids induce liver glucose-6-phosphatase expression in rainbow trout (Oncorbynchus mykiss). J Nutr 132, 137-141.
225. Figueiredo-Silva AC, Panserat S, Kaushik S, et al. (2012) High levels of dietary fat impair glucose homeostasis in rainbow trout. J Exp Biol 215, 169-178.

226. Figueiredo-Silva AC (2009) Nutritional Regulation of Lipid Deposition in Blackspot Seabream (Pagellus bogaraveo). Porto: University of Porto.

227. Kirchner S, Kaushik S \& Panserat S (2003) Low protein intake is associated with reduced hepatic gluconeogenic enzyme expression in rainbow trout (Oncorbynchus mykiss). J Nutr 133, 2561-2564.

228. Tapia-Salazar M, Bureau W, Panserat S, et al. (2006) Effect of DHA supplementation on digestible starch utilization by rainbow trout. Br J Nutr 95, 76-87.

229. Kirchner S, Kaushik S \& Panserat S (2003) Effect of partial substitution of dietary protein by a single gluconeogenic dispensable amino acid on hepatic glucose metabolism in rainbow trout (Oncorbynchus mykiss). Comp Biochem Physiol A Mol Integr Physiol 134, 337-347.

230. Geurden I, Aramendi M, Zambonino-Infante J, et al. (2007) Early feeding of carnivorous rainbow trout (Oncorbynchus mykiss) with a hyperglucidic diet during a short period: effect on dietary glucose utilization in juveniles. $A m \mathrm{~J}$ Physiol Regul Integr Comp Physiol 292, R2275-R2283.

231. Panserat S, Fontagné S, Bergot P, et al. (2001) Ontogenesis of hexokinase I and hexokinase IV (glucokinase) gene expressions in common carp (Cyprinus carpio) related to diet. BrJ Nutr 85, 649-651.

232. Naylor RL, Hardy RW, Bureau DP, et al. (2009) Feeding aquaculture in an era of finite resources. Proc Natl Acad Sci U S A 106, 15103-15110.

233. Gómez-Requeni P, Mingarro M, Kirchner S, et al. (2003) Effects of dietary amino acid profile on growth performance, key metabolic enzymes and somatotropic axis responsiveness of gilthead sea bream (Sparus aurata). Aquaculture 220, 749-767.

234. Panserat S, Skiba-Cassy S, Seiliez I, et al. (2009) Metformin improves postprandial glucose homeostasis in rainbow trout fed dietary carbohydrates: a link with the induction of hepatic lipogenic capacities? Am J Physiol Regul Integr Comp Physiol 293, R707-R715.

235. Lansard M, Panserat S, Seiliez I, et al. (2009) Hepatic protein kinase B (Akt)-target of rapamycin (TOR)signalling pathways and intermediary metabolism in rainbow trout (Oncorhynchus mykiss) are not significantly affected by feeding plant-based diets. Br J Nutr 102, $1564-1573$.

236. Sissener NH, Hemre GI, Espe M, et al. (2012) Effects of plant-based diets on glucose and amino acid metabolism, leptin, ghrelin and GH-IGF system regulation in Atlantic salmon (Salmo salar L.). Aquac Nutr 19, 399-412.

237. Polakof S, Skiba-Cassy S, Choubert G, et al. (2010) Insulininduced hypoglycaemia is co-ordinately regulated by liver and muscle during acute and chronic insulin stimulation in rainbow trout (Oncorbynchus mykiss). J Exp Biol 213, $1443-1452$.

238. Plagnes-Juan E, Lansard M, Seiliez I, et al. (2008) Insulin regulates the expression of several metabolism-related genes in the liver and primary hepatocytes of rainbow trout (Oncorbynchus mykiss). J Exp Biol 211, 2510-2518.

239. Egea M, Meton I \& Baanante IV (2007) Sp1 and Sp3 regulate glucokinase gene transcription in the liver of gilthead sea bream (Sparus aurata). J Mol Endocrinol 38, 481-492.

240. Egea M, Metón I, Córdoba M, et al. (2008) Role of Sp1 and SREBP-1a in the insulin-mediated regulation of glucokinase transcription in the liver of gilthead sea bream (Sparus aurata). Gen Comp Endocrinol 155, 359-367. 
241. Tranulis MA, Christophersen B \& Borrebaek B (1997) Glucokinase in Atlantic halibut (Hippoglossus hipoglossus) Brockmann bodies. Comp Biochem Physiol B Biochem Mol Biol 116, 367-370.

242. Polakof S, Míguez JM \& Soengas JL (2008) Changes in food intake and glucosensing function of hypothalamus and hindbrain in rainbow trout subjected to hyperglycemic or hypoglycemic conditions. J Comp Physiol A Neuroethol Sens Neural Behav Physiol 194, 829-839.

243. Polakof S, Míguez JM \& Soengas JL (2008) Dietary carbohydrates induce changes in glucosensing capacity and food intake of rainbow trout. Am J Physiol Regul Integr Comp Physiol 295, R478-R489.

244. Polakof S, Panserat S, Plagnes-Juan E, et al. (2008) Altered dietary carbohydrates significantly affect gene expression of the major glucosensing components in Brockmann bodies and hypothalamus of rainbow trout. Am J Physiol Regul Integr Comp Physiol 295, R1077-R1088.

245. Polakof S, Míguez JM \& Soengas JL (2007) In vitro evidences for glucosensing capacity and mechanisms in hypothalamus, hindbrain, and Brockmann bodies of rainbow trout. Am J Physiol Regul Integr Comp Physiol 293, R1410-R1420.

246. Polakof S \& Soengas JL (2008) Involvement of lactate in glucose metabolism and glucosensing function in selected tissues of rainbow trout. J Exp Biol 211, 1075-1086.

247. Polakof S, Alvarez R, Soengas JL, et al. (2010) Gut glucose metabolism in rainbow trout: implications in glucose homeostasis and glucosesensing capacity. Am J Physiol Regul Integr Comp Physiol 299, R19-R32.

248. Matschinsky FM, Zelent B, Doliba N, et al. (2011) Glucokinase activators for diabetes therapy: May 2010 status report. Diabetes Care 34, S236-S243.

249. Papadopoulos JS \& Agarwala R (2007) COBALT: constraintbased alignment tool for multiple protein sequences. Bioinformatics 23, 1073-1079.
250. Ureta T, Radojković J, Zepeda S, et al. (1981) Comparative studies on glucose phosphorylating isoenzymes of vertebrates. VII. Mammalian hexokinases. Comp Biochem Physiol B 70, 225-236.

251. Pilkis SJ, Hansen RJ \& Krahl ME (1968) Hexose-ATP phosphotransferases: comparative aspects. Comp Biochem Physiol 25, 903-912.

252. Emmanuel B (1981) Glucokinase, hexokinase, gluconeogenesis, glycogenesis and glycolysis in camel (Camelus dromedarius) and sheep (Ovis aries). Comp Biochem Physiol B 68, 547-550.

253. Ballard FJ (1965) Glucose utilization in mammalian liver. Comp Biochem Physiol 14, 437-443.

254. Ferre T, Riu E, Bosch F, et al. (1996) Evidence from transgenic mice that glucokinase is rate limiting for glucose utilization in the liver. FASEB J 10, 1213-1218.

255. Wallace JC \& Newsholme EA (1967) A comparison of the properties of fructose 1,6-diphosphatase, and the activities of other key enzymes of carbohydrate metabolism, in the livers of embryonic and adult rat, sheep and domestic fowl. Biochem J 104, 378-384.

256. Ureta T, Slebe JC, Radojković J, et al. (1975) Comparative studies on glucose phosphorylating isoenzymes of vertebrates. V. Glucose phosphotransferases in the liver of reptiles. Comp Biochem Physiol B 50, 515-524.

257. Figueiredo-Silva AC, Corraze G, Kaushik S, et al. (2010) Modulation of blackspot seabream (Pagellus bogaraveo) intermediary metabolic pathways by dispensable amino acids. Amino Acids 39, 1401-1416.

258. Sharma C, Manjeshwar R \& Weinhouse S (1964) Hormonal and dietary regulation of hepatic glucokinase. Adv Enzyme Regul 2, 189-200.

259. Kirchner S, Panserat S, Lim PL, et al. (2008) The role of hepatic, renal and intestinal gluconeogenic enzymes in glucose homeostasis of juvenile rainbow trout. $J$ Comp Physiol B Biochem Syst Environ Physiol 178, 429-438. 